\title{
10. Die Sperrmaßnahmen am 13. August 1961 und die anschließenden Konflikte
}

\section{Durchführung der Sperrmaßnahmen in und um Berlin}

Nach der Rückkehr Ulbrichts von der Moskauer Tagung des Politischen Konsultativkomitees bereitete die DDR die Sperrung der Sektorengrenze vor. Zwei ostdeutsche Divisionen, die vorher zu angeblichen Manövern in den Großraum Berlin gebracht worden waren, wurden in die Nähe der abzuriegelnden Grenze verlegt. Auch andere Maßnahmen ließen die Gefahr entstehen, daß die westliche Seite einen bevorstehenden Angriff auf West-Berlin vermutete und darauf militärisch reagierte. Dieses Mißverständnis suchte man auf alle mögliche Weise zu verhindern. Als die westlichen Stadtkommandanten von Berlin während eines Empfangs am 10. August 1961 Besorgnis über Truppenbewegungen im Umland äußerten, erklärte der Oberbefehlshaber der sowjetischen Streitkräfte in Deutschland, Marschall Konew: „Meine Herren, Sie können beruhigt sein. Was immer in absehbarer Zukunft geschehen wird - Ihre Rechte werden unangetastet bleiben, und nichts wird sich gegen West-Berlin richten."1 Direkt an der Grenze kamen nur Polizeikräfte zum Einsatz, deren Auftrag auf unbewaffnete Aktionen - Unterbrechung des Personen- und Fahrzeugverkehrs und Errichtung von Drahtverhauen - beschränkt war. In der zweiten Reihe nahmen Militäreinheiten der DDR Aufstellung; erst hinter ihnen standen sowjetische Formationen. Mit zunehmendem Kampfcharakter einer Truppe vergrößerte sich mithin ihr Abstand von der möglichen Front. Auch der Umstand, daß Panzer unter offensichtlichem Verzicht auf Tarnung auffuhren, zeigte ein „demonstratives, nicht kampfmäßiges Vorgehen“ an. Jeder „Anknüpfungspunkt für Provokationen“ war zu vermeiden, um die Westemächte über die östlichen Absichten zu beruhigen. Sollte es trotzdem zu einer „imperialistischen Aggression“ kommen, planten die sowjetischen und ostdeutschen Militärs koordinierte Operationen. ${ }^{2}$

Auch zuvor schon waren Vorbereitungen für einen möglichen Konflikt getroffen worden. Die damalige Ausrichtung bedurfte jetzt der Änderung. Hatte der Nationale Verteidigungsrat der DDR Anfang 1961 für 15. Juli bis 31. Oktober

1 Richard Reeves, President Kennedy. Profile of Power, New York 1993, S. 207.

2 Notiz über die Absprache zwischen dem Chef des Stabes der Gruppe der sowjetischen Streitkräfte in Deutschland, Genossen Generalleutnant Arikow [sic], und dem Stellvertreter des Ministers für Nationale Verteidigung und Chefs des Hauptstabes, Genossen Generalmajor Riedel, 25. 7. 1961, BArch-MArch, VA-01/18771, Bl. 13 f.; NVA/Institut für Militärgeschichte, Die Nationale Volksarmee in der Aktion vom 13. August 1961, Hauptbearbeiter: Kapitän zur See Glaser, 20. 2. 1964, BArch-MArch, VA-01/14835, Bl. 47 f., 59f. (hier die Zitate). Die gestaffelte Aufstellung wird auch von Chruščëvs Sohn erwähnt (Sergej Chruščëv, Roždenie sverchderžavy. Kniga ob otce, Moskau 2000, S. 401). 
zwecks „größerer Dichte der Grenzsicherung“ gegenüber Westdeutschland eine Umgruppierung und Neubewaffnung der paramilitärischen Polizeikräfte angeordnet, während in Berlin „nur eine gewisse Überwachung des grenzüberschreitenden Verkehrs“ vorgesehen war, erhielt die Polizei nach der Moskauer Tagung den Auftrag, „in kurzer Zeit und in hoher Qualität die grundlegenden Dokumente für den Einsatz der Verbände in und um Berlin zu erarbeiten." In nur drei Tagen entstand eine stabsmäßige Durchführungsplanung, deren Autoren freilich bis zum 12. August abends - als die Formationen in ihre Einsatzorte eingewiesen wurden - nicht wußten, wann die Operation stattfinden sollte. ${ }^{3}$

Polizei und Militär rückten wie geplant in die vorgesehenen Abschnitte ein, ohne daß die westliche Seite vor dem Beginn der Aktion darauf aufmerksam wurde. Insofern konnten die Sicherheitskräfte der DDR zu recht in ihrer internen Bilanz eine hervorragende organisatorische Leistung feststellen, die bei nur kurzer Vorbereitung erzielt worden war. An der Grenze herrschten dagegen zu Anfang weithin Chaos und Desorganisation. Für die Befehlshaber vor Ort waren die Sperrmittel oft nicht bereitgestellt worden. Soweit diese nicht zufällig vorhanden waren, mußten sie erst herangeschafft werden. Zuweilen riß man die Straße auf, um Pflastersteine zur Errichtung provisorischer Sperren zu haben, oder man entnahm nahegelegenen Baustellen Hohlblocksteine, die für die Schaffung von Wohnraum vorgesehen gewesen waren. Im Umgang mit Situationen, die durch fliehende oder protestierende Menschen entstanden, waren die Sicherheitskräfte oft unsicher und nervös, weil sie kaum Einweisung erhalten hatten. Zuerst beschränkte sich die Grenzsicherung auf scharfe Kontrollen, Zurückweisung von DDR-Bewohnern auf dem Weg nach Westen und Aufbau einzelner Stacheldrahtverhaue. Erst nach einigen Tagen begann die systematische Errichtung durchgehender Sperranlagen. Auch danach erfolgten zahlreiche Grenzdurchbrüche, die oft auch durch Gebrauch von Schußwaffen - mit einem ersten Todesopfer am 23. August - nicht verhindert werden konnten.

Nachdem in Berlin die freie Bewegung über die Sektorengrenze unterbunden worden war, nahmen an der Grenze zur Bundesrepublik die illegalen Übertritte stark zu. Die UdSSR ermächtigte daher das SED-Regime zum Ausbau der dortigen Sperranlagen. Marschall Konew wies den Verteidigungsminister der DDR in einem Schreiben vom 14. September 1961 an, dort neben sonstigen Hindernissen „Drahtsperren, Minenfelder, Signalvorrichtungen, Beobachtungstürme und einen Kontroll- und Patrouillenstreifen anzulegen." Soweit das möglich und bisher noch nicht erfolgt sei, sollte die Bevölkerung aus der 1952 geschaffenen „5 kmSchutzzone“ ausgesiedelt werden. Für den Zugang zu Ortschaften, die weiterhin bestehen blieben, wurden rigorose Beschränkungen und Kontrollen vorgesehen. Zur Bewachung der Grenze waren „ausreichende Kräfte“ einzusetzen. Dienstverletzungen, vor allem auch „Untätigkeit bei vorliegender Notwendigkeit der Anwendung der Waffe“, sollten scharf geahndet werden. ${ }^{4}$ Im Blick auf West-Berlin wurde grundsätzlich das gleiche Kontrollregime vorgesehen, doch erzwang die

NVA/Institut, a.a.O., S. 21-27.

4 I. Konev an H. Hoffmann, 14. 9. 1961, in: Beiträge zur Geschichte der Arbeiterbewegung, 2/1997, S. $90-92$. 
sehr dichte Besiedlung, vor allem im Stadtgebiet, an vielen Stellen Abstriche. So war oft keine $5 \mathrm{~km}$ tiefe Staffelung möglich. Konew wollte zudem die in Grenznähe lebende West-Berliner Bevölkerung nicht gefährden und ordnete daher an, die „Ordnung für die Anwendung von Waffengewalt“ gegenüber der Praxis an der Grenze zur Bundesrepublik zu differenzieren. ${ }^{5}$ Auch ließen sich im Stadtbereich Minensperren und Hindernisstreifen kaum anlegen. Am 18. Oktober wurde in noch begrenztem Rahmen ein „verstärkte[r] Ausbau der Grenzsicherungsanlagen entlang der Staatsgrenze zu Westberlin“ befohlen. ${ }^{6}$

\section{Östliche Einschätzungen des erzielten Erfolgs}

Am frühen Morgen des 13. August 1961 war die westliche Überraschung perfekt. Zwar war in Washington auch an die Möglichkeit gedacht worden, daß die östliche Seite an der Sektorengrenze „drastische Schritte“ zur Kontrolle des Flüchtlingsstroms einleiten könnte. Damit hatte jedoch kaum jemand ernstlich gerechnet, weil man die DDR als Dampfkessel ansah, der zur Verhinderung einer Explosion ein Sicherheitsventil benötigte. Zudem war die Aufmerksamkeit auf die Drohung mit dem separaten Friedensvertrag fixiert. Allen anderen Anzeichen war daher wenig Beachtung geschenkt worden. ${ }^{7}$ Nicht zuletzt wegen der gelungenen Überraschung wertete Ulbricht die Grenzsperrung als vollen Erfolg. Er berichtete Chruschtschow voller Stolz, der Beschluß sei „planmäßig“ verwirklicht worden. Die „Taktik, schrittweise die Maßnahmen durchzuführen“, habe es „dem Gegner erschwert, sich über das Ausmaß unserer Maßnahmen zu orientieren, und uns erleichtert, die schwachen Stellen an der Grenze zu finden.“ Der Westen habe „weniger Gegenmaßnahmen unternommen [...], als zu erwarten war."8 Honecker, dem Ulbricht die Durchführung der Sperrmaßnahmen übertragen hatte, sprach ebenfalls von sehr guten Ergebnissen. Es seien „keinerlei ernstliche Komplikationen“ aufgetreten. Positiv sei auch, daß das „Bündnis der Arbeiter und Bauern in der DDR“ am 13. August die Prüfung bestanden habe, die Mehrheit der Intelligenz im Lande unverhoffte Zustimmung erkennen lasse und die Situation der Jugend sich stabilisiere. Die Versorgungslage habe sich gebessert, und die „feindlichen Elemente" unternähmen keine ernstlichen Aktivitäten. ${ }^{9}$

Die Reaktion der USA entsprach den Wünschen der östlichen Seite. Als Kennedy am Vormittag des 13. August beim sonntäglichen Segeln die Nachricht erhielt, sah er keinen Grund zum Handeln. Eine Grenzschließung, so sein interner

5 Ebd., S. 92.

6 NVA/Institut, a.a.O., Bl. 7.

7 John C. Ausland, Kennedy, Khrushchev, and the Berlin-Cuba Crisis 1961-1964, Oslo - Stockholm - Copenhagen - Boston 1996, S. 15 f., 21 f., 116-120. Zur Frage, ob entweder die westlichen Geheimdienste versagt oder amerikanische Regierungsstellen im vorhinein Einverständnis bekundet hätten, siehe Honoré M. Catudal, Kennedy and the Berlin Wall Crisis. A Case Study in U.S. Decision Making, [West-]Berlin 1980, S. 25-35, 216-219, 229-250.

8 W. Ulbricht an N.S. Chruščëv, 16. 9. 1961, SAPMO-BArch, DY 30/3509, Bl. 95-104.

9 G. Žiljakov, Zapis' informacii t. Chonnekera dlja glav dipomatičeskich predstavitel'stv socialističeskich stran v GDR [8. 9. 1961], o.D., RGANI, 5, 49, 385 (rolik 8981), Bl. 191-200. 
Kommentar, sei allemal besser als ein Krieg. ${ }^{10}$ Der Protest, der bei sowjetischen Eigenmächtigkeiten im Vier-Mächte-Gebiet Berlin üblich war, erfolgte mit Verzögerung und nur auf der unteren Ebene der Stadtkommandanten. ${ }^{11}$ Das rief den Eindruck bloßer Routine hervor und erleichterte der UdSSR die Zurückweisung. ${ }^{12}$ In der Tat war der Präsident ohne weiteres bereit, den veränderten Status quo zu akzeptieren. In seiner Sicht war die Stabilität im geteilten Deutschland, die durch eine kollabierende DDR gefährdet worden wäre, ein grundlegendes Erfordernis von Frieden und Verständigung. Die Sperrung der Sektorengrenze war für ihn eine durch die Lage im SED-Staat bedingte Notmaßnahme, ${ }^{13}$ mit der er die Erwartung verband, daß die östliche Seite die bisherigen weitergehenden Forderungen fallen lasse. ${ }^{14}$ Dadurch glaubte er seinem Ziel eines wechselseitig zufriedenstellenden Kompromisses in Berlin ${ }^{15}$ nähergekommen zu sein. Das war freilich ein Irrtum. Chruschtschow war keineswegs willens, vom Verlangen nach Schaffung einer „Freien Stadt“ und nach Übergabe der Zugangswege an die DDR abzugehen. ${ }^{16}$

Ulbricht triumphierte. Nicht nur hätten die von West-Berlin ausgehenden Störwirkungen ein Ende gefunden. Es sei auch eine generelle „Aenderung [sic] der politischen Lage“ eingetreten. In Bonn habe man begriffen, daß die „Revanchepolitik“ und der „Plan, durch die Organisierung des Bürgerkrieges und des kleinen Krieges die DDR aufzurollen, ein für allemal gescheitert“ seien. Davon seien für später „große Auswirkungen auf die Taktik der Westmächte gegenüber Polen und der Tschechoslowakei“ zu erwarten. Die Autorität der ostdeutschen Staatsmacht sei gestärkt; im Denken der Bevölkerung zeichne sich ein Umschwung ab. Weil keine Westbesucher mehr kämen, habe sich die Versorgung in Ost-Berlin konsolidiert. Nunmehr gerate der Westteil der Stadt in zunehmende Schwierigkeiten. Bonn sei genötigt, die Subventionen stark zu erhöhen; „viele Angehörige der Bourgeoisie“ zögen in die Bundesrepublik um. Es zeige sich, daß West-Berlin selbst bei gesicherten Außenverbindungen nur noch mit „normalen Beziehungen“ zur DDR eine Zukunft habe. ${ }^{17}$

10 H. M. Catudal, a.a.O., S. 35-39; Jean Edward Smith, Lucius D. Clay, New York 1990, S. 637; R. Reeves, a.a.O., S. 209-212.

11 Note der drei westlichen Stadtkommandanten von Berlin an ihr sowjetisches Gegenüber, 15. 8. 1961, ín: Documents on Germany 1944-1985, Department of State Publication 9446, Washington/ DC 1985, S. $776 \mathrm{f}$.

12 Entwurf des sowjetischen Außenministeriums für die Antwort des sowjetischen Ortskommandanten in Berlin auf den Protest der westlichen Stadtkommandanten vom 15.8. 1961, o.D., AVPRF, 0129, 45, 329, 13, Bl. $12 \mathrm{f}$.

13 Udo Wetzlaugk, Berlin und die deutsche Frage, Köln 1985, S. 166 f.

14 H. M. Catudal, a.a.O., S. 35-39; J. E. Smith, Lucius D. Clay, a.a.O., S. 637; R. Reeves, a.a.O., S. 209-212.

15 Vgl. seine Äußerung gegenüber Adenauer im Juni 1961, wiedergegeben bei Hans-Peter Schwarz, Adenauer. Der Staatsmann 1952-1967, Stuttgart 1991, S. 707.

16 Die Forderung nach Friedensvertrag und Freistadtregelung war demgemäß ein wesentliches Thema der Propaganda, die am 13. 8. 1961 aufgrund der am Monatsanfang gefaßten Beschlüsse anlief (vgl. Beschluß des ZK der KPdSU, Anlage 2: Maßnahmen zu Propaganda-Fragen, 1. 8. 1961, AVPRF, 0742, 6, 34, 46, Bl. 135-137; Protokol No. 340 zasedanija Prezidiuma Central'nogo Komiteta KPSS. Ot 4.VIII.61g.: O napravlenija poslanija tov. N. S. Chruščëva [Billigung des Beschlusses des Politischen Konsultativkomitees], 12. 4. 1961, RGANI, 3, 14, 496, Bl. 12-24, insbes. 17-19).

17 W. Ulbricht an N. S. Chruščëv, 16. 9. 1961, SAPMO-BArch, DY 30/3509, Bl. 95-104. 
Honecker versicherte den Ost-Berliner Botschaftern der anderen sozialistischen Staaten, daß nun ein „neues Kräfteverhältnis in der Welt“ bestehe, und stellte den „Bankrott der Politik von Adenauer und Strauß gegenüber der DDR“ fest, was „sehr großen Eindruck auf die Bevölkerung Deutschlands“ gemacht habe. Es werde immer klarer, daß die Welt mit der DDR rechnen müsse. Zudem hätten die Ostdeutschen nun eine Entwicklungsperspektive erhalten. Auch wenn die Errichtung der Staatsgrenze innerhalb Berlins vom Standpunkt des nationalen Bewußtseins eine harte Sache gewesen sei, habe die Bevölkerung der DDR die Notwendigkeit eingesehen. Ähnlich wie Ulbricht hob auch Honecker die Schwierigkeiten hervor, denen sich West-Berlin nunmehr gegenübersehe. ${ }^{18}$ Chruschtschow hielt die Aktion ebenfalls für einen Erfolg. Anders als die SED-Führung war er sich aber nicht sicher, ob die Bereinigung der "Situation in Mitteleuropa“ damit schon gewährleistet war. ${ }^{19}$

In innenpolitischer Hinsicht schuf die Sperrung der Sektorengrenze für Moskau und Ost-Berlin die Voraussetzung, daß die Ziele des Sozialismus in der DDR ohne die bisher hemmenden Rücksichten verfolgt werden konnten. Auch der militärische Aufbau wurde erleichtert. Solange zu befürchten gewesen war, daß die jungen Männer, die meist nicht für das „sozialistische Vaterland“ zur Waffe greifen wollten, sich einer Rekrutierung für die Nationale Volksarmee durch die Flucht entziehen würden, war an einen obligatorischen Militärdienst nicht zu denken. Mit der Grenzschließung in Berlin änderte sich das. Im September beschloß die DDR zunächst ein allgemeines Verteidigungsgesetz. Am 24. Januar 1962 wurde auf Initiative des Kreml20 die Wehrpflicht eingeführt. ${ }^{21}$

\section{Bemühungen Chruschtschows}

Ungeachtet aller gewonnenen Vorteile, war Chruschtschow besorgt, denn ihm war klar, daß die Abriegelung West-Berlins in der Öffentlichkeit einen schlechten Eindruck hervorrief. Er leitete daher nicht nur von allem Anfang an eine intensive Rechtfertigungskampagne ein,22 sondern suchte auch mit einem publikumswirksamen Angebot moralisch in die Offensive zu gehen. Deshalb hatte er Ulbricht dazu bewogen, sein Plädoyer im Plenum des Politischen Konsultativkomitees für die Schließung der Sektorengrenze mit der Zusicherung zu verbinden, West-Berliner dürften die Hauptstadt der DDR „mit besonderer Bescheinigung“ besu-

18 G. Žiljakov, Zapis' informacii t. Chonnekera dlja glav dipomatičeskich predstavitel'stv socialističeskich stran v GDR [8. 9. 1961], o.D., RGANI, 5, 49, 385 (rolik 8981), Bl. 191-194.

19 N. S. Chruščëv an W. Ulbricht (dte. Übers.), 28. 9. 1961, SAPMO-BArch, DY 30/3509, Bl. 105 f.

20 Botschafter Dölling an O. Winzer, 28. 12. 1961, PA-MfAA, G-A 478, B1. 25; Aktenvermerk Gespräch Krolikowski - Žiljakov in Moskau, 19. 1. 1962, PA-MfAA, G-A 478, Bl. 26-30.

21 Rüdiger Wenzke, Die Nationale Volksarmee (1956-1990), in: Torsten Diedrich/Hans Ehlert/Rüdiger Wenzke (Hrsg.), Im Dienste der Partei. Handbuch der bewaffneten Organe der DDR, Berlin 1998, S. $442 \mathrm{f}$.

22 Beschluß des ZK der KPdSU, Anlage 2: Maßnahmen zu Propaganda-Fragen, 1. 8. 1961, AVPRF, 0742, 6, 34, 46, Bl. 135-137; Protokol No. 340 zasedanija Prezidiuma Central'nogo Komiteta KPSS. Ot 4.VIII.61g.: O napravlenija poslanija tov. N. S. Chruščëva [Billigung des Beschlusses des Politischen Konsultativkomitees], 12. 4. 1961, RGANI, 3, 14, 496, Bl. 12-24. 
chen. ${ }^{23}$ Das Innenministerium der DDR kündigte am 22. August die Erteilung von Aufenthaltsgenehmigungen an. Die Anträge seien in zwei Büros zu stellen, die nach seinen Weisungen in den Westsektoren tätig werden sollten. Senat und Besatzungsmächte sahen darin den Versuch, administrative Stützpunkte auf WestBerliner Gebiet zu etablieren und so eine Machtposition aufzubauen, welche die oberste Gewalt der Westmächte beeinträchtige und dem östlichen Freistadtplan Vorschub leiste. Sie sahen den Argwohn durch die Tatsache bestätigt, daß die DDR auch sonst in West-Berlin institutionelle Positionen zu schaffen suchte. Daher wurde die Tätigkeit der Passierscheinbüros verboten. ${ }^{24}$ Die östliche Propaganda wies daraufhin der westlichen Seite die Schuld am unterbundenen Kontakt zwischen den Menschen der geteilten Stadt zu. ${ }^{25}$

Der Kreml bereitete sich darauf vor, den Abschluß des Friedensvertrages und die nachfolgende Freistadtregelung bis zum Jahresende entweder im Zusammenwirken mit den Westmächten oder in einseitig östlichem Rahmen durchzusetzen. Außenminister Gromyko erhielt den Auftrag, darüber mit den USA im September zu sprechen. Bis Oktober sollte eine Vorlage für die Erörterung des Separatvertrags mit der DDR formuliert sein. ${ }^{26}$ Ulbricht sah daher die Zeit gekommen, nicht nur die Westmächte aus West-Berlin zu vertreiben, sondern anschließend auch die „Lösung der nationalen Frage des deutschen Volkes“ durch „die Überwindung des deutschen Imperialismus, die Befreiung Westdeutschlands von den Fesseln der Pariser Verträge und der NATO und den Abzug der ausländischen Truppen aus Westdeutschland“ ins Auge zu fassen. Der „Sieg des Sozialismus in der DDR“ sollte ausdrücklich die Grundbedingung für die Einheit Deutschlands sein. ${ }^{27}$ Chruschtschow spannte seine Erwartungen zwar weniger weit, hielt aber ebenfalls die „Position in der Frage des Abschlusses eines deutschen Friedensvertrages und der Normalisierung der Lage in Westberlin auf dieser Grundlage“ für gestärkt. Er hoffte, diese Regelung lasse sich möglicherweise zusammen mit den Westmächten - also ohne Konfrontation - verwirklichen, weil nun viele westliche Politiker die Lage „nüchterner“ einschätzten.28

23 Rede von W. Ulbricht im Plenum des Politischen Konsultativkomitees, 4. 8. 1961, wiedergegeben in: Beiträge zur Geschichte der Arbeiterbewegung, 2/1997, S. 70 f.

24 Document 02941, Crisis Over Berlin. American Policy Concerning the Soviet Threats to Berlin, November 1958-December 1962. Part VI: June-September 1961, Research Project No. 614-F, April 1970, Department of State (Documents from the National Security Archive, microfiches published by Chadwyck-Healey Inc.), S. 96; TASS-Bericht aus Berlin [nicht zur Veröffentlichung, sondern zur internen Information bestimmt], 16. 12. 1961, AVPRF, 568, 20, 972, 226, o.B1.; Gerhard Kunze, Grenzerfahrungen. Kontakte und Verhandlungen zwischen dem Land Berlin und der DDR 1949-1989, Berlin 1999, S. $41 \mathrm{f}$.

25 Vgl. hierzu beispielsweise die einschlägige Hauptüberschrift auf Seite 1 des SED-Zentralorgans „Neues Deutschland“ am 27. 8. 1961: „Befehl der Besatzer gestern in Westberlin: Brandt-Polizei verbietet Besuch im demokratischen Berlin [d.h. in Ost-Berlin]. Westberliner brutal terrorisiert“. Unter der weiteren Überschrift „Erschütternde Szenen auf S-Bahnhöfen“ war von den „berüchtigten Schlägergarden des Frontstadtsenats“ die Rede, die sich auf Hunderte wartender Antragsteller gestürzt hätten, die „dankbar das Entgegenkommen der DDR-Regierung“ nutzen wollten.

26 Vladislav M. Zubok, Khrushchev’s Motives and Soviet Diplomacy in the Berlin Crisis, 1958-1962, Arbeitspapier für die internationale wissenschaftliche Konferenz „The Soviet Union, Germany, and the Cold War, 1945-1962, Essen, 28.-30. 6. 1994, S. 32.

27 W. Ulbricht an N. S. Chruščëv, 16. 9. 1961, SAPMO-BArch, DY 30/3509, Bl. $101 \mathrm{f}$.

28 N. S. Chruščëv an W. Ulbricht (dte. Übers.), 28. 9. 1961, SAPMO-BArch, DY 30/3509, Bl. 105. 


\section{Reaktionen im Westen}

Kennedy sah keinen Grund zur Aufregung über das östliche Vorgehen in Berlin, ja, er war geradezu erleichtert darüber, daß „nur“ die Grenze gesperrt wurde. Ein kriegsträchtiger Konflikt schien dadurch endgültig vermieden.29 Sein Gleichmut ließ den psychologischen Eindruck der Maßnahme bei den Deutschen außer acht. Besonders die West-Berliner Bevölkerung erlitt einen Schock. Sie sah sich von der Umgebung abgeschnitten und fühlte sich ohne Unterstützung der USA feindlicher Willkür preisgegeben. Soeben war ihre Stadt noch der Ort gewesen, der den Deutschen aus West und Ost unkontrollierten Kontakt ermöglichte, den „aus der Unfreiheit Fliehenden“ ein Schlupfloch bot und für die DDR-Bürger ein bewundertes "Schaufenster des Westens“ war - und nun war das auf einen Schlag zu Ende, ohne daß dies die amerikanische Schutzmacht, auf deren Rückhalt man gebaut hatte, irgendwie zu berühren schien. Der Regierende Bürgermeister, Willy Brandt, wandte sich mit einem verzweifelten Brief an Kennedy, 30 den dieser kühldistanziert beantwortete. Auch in Bonn herrschten Verstörung und Ratlosigkeit über die Gleichgültigkeit, die der Präsident gegenüber den Gefühlen und Interessen des deutschen Verbündeten an den Tag legte. ${ }^{31}$

Es bedurfte energischer Hinweise von Beratern und Mitarbeitern, bis Kennedy begriff, daß seine Haltung die westliche Position in Berlin untergrub. Wie man ihm weiter klarmachte, drohte das von ihm beabsichtigte baldige Verhandlungsangebot an die UdSSR die psychologische Lage vollends $\mathrm{zu}$ destabilisieren. ${ }^{32}$ Nachdem der Präsident das Problem erkannt hatte, handelte er schnell und entschlossen. Dem Protest der westlichen Stadtkommandanten ließ er zwei Tage später eine regierungsamtliche Note folgen. ${ }^{33}$ Vor allem jedoch sandte er Vizepräsident Johnson als Botschafter des amerikanischen Engagements in die bedrängte Stadt, setzte einen Militärkonvoi dorthin in Bewegung (der von sowjetischer Seite nicht behindert wurde) und ernannte den „Helden der Blockade“ von 1948/49,

29 Demgegenüber erklärt Harald Biermann, John F. Kennedy und der Kalte Krieg. Die Außenpolitik der USA und die Grenzen der Glaubwürdigkeit, Paderborn 1997, S. 136, Kennedy habe den Mauerbau schon damals nicht als Ende der politischen Offensive betrachtet, sondern eine weitere Eskalation der Krise vorausgesehen. Dem wird von allen anderen Autoren widersprochen, siehe u.a. Frank A. Mayer, Adenauer and Kennedy: A Study in German-American Relations, 1961-1963, New York 1996, S. 43 f.; Michael Beschloss, The Crisis Years. Kennedy and Khrushchev 19601963, NewYork 1991, S. 278; James N. Giglio, The Presidency of John F. Kennedy, Lawrence/KS 1991, S. $83 \mathrm{f}$.

30 W. Brandt an J. F. Kennedy, 16. 8. 1961, in: Wolfgang Heidelmeyer/Günter Hindrichs (Bearb.), Dokumente zur Berlin-Frage 1944-1962. Mit einem Vorwort von Willy Brandt, München 1962, S. $479 \mathrm{f}$.

31 Siehe u.a. Christof Münger, Kennedy, die Berliner Mauer und die Kubakrise. Die westliche Allianz in der Zerreißprobe, Paderborn 2003, S. 102-105; Horst Osterheld, „Ich gehe nicht leichten Herzens...“. Adenauers letzte Kanzlerjahre - ein dokumentarischer Bericht, Mainz 1987 (2. Aufl.), S. 59-63.

32 Document 02941, Crisis Over Berlin. American Policy Concerning the Soviet Threats to Berlin, November 1958-December 1962. Part VI: June-September 1961, Research Project No. 614-F, April 1970, Department of State (Documents from the National Security Archive, microfiches published by Chadwyck-Healey Inc.), S. 89-91.

33 Note der USA an die UdSSR, 17. 8. 1961, in: Documents on Germany, a.a.O., S. 777 f. 
General Clay, zu seinem persönlichen Repräsentanten in Berlin. Das rief Jubel in der Bevölkerung hervor; die akute Vertrauenskrise wurde überwunden. ${ }^{34}$

\section{Auseinandersetzungen im Gefolge der Sperrmaßnahmen}

Die DDR-Polizei machte von der Schußwaffe Gebrauch, wenn es galt, Grenzdurchbrüche zu verhindern. Sie holte sogar mehrfach Flüchtlinge zurück, die westliches Gebiet erreicht hatten. Dadurch wurden trotz sowjetischen Dringens auf Zurückhaltung immer wieder West-Berliner in Gefahr gebracht. Die ostdeutschen Organe setzten auch Tränengas, Wasserwerfer und Warnschüsse gegen Demonstranten ein, die an der Sektorengrenze protestierten. Die amerikanischen Besatzungsbehörden vermuteten, damit solle ein 100 Meter breiter Streifen Niemandsland auf westlicher Seite erzwungen werden, und erhoben bei der sowjetischen Seite Einspruch mit dem Argument, dieses Vorgehen sei geeignet, die bereits "gefährlich gespannte Situation“ weiter zu verschärfen. Der Westen werde, wenn es nicht beendet werde, darauf entsprechend reagieren. ${ }^{35}$ Aus Prinzip verweigerte der sowjetische Stadtkommandant die Entgegennahme des Protests: Die Sache falle nicht in seine Zuständigkeit. ${ }^{36}$ Intern jedoch gab der Kreml der SED-Führung zu verstehen, daß er das Verhalten mißbilligte. Dieses könnte „unerwünschte ernste Folgen“ nach sich ziehen. ${ }^{37}$ General Clay, der keine Anzeichen für ein Abgehen der DDR von der bisherigen Praxis sah, schickte Militärpatrouillen an die Grenze. ${ }^{38}$ Daraufhin warfen die sowjetischen Behörden den Amerikanern vor, eine „anomale Lage“ zu schaffen, die „Hooligan-Elemente“ zu „provokatorischen Ausschreitungen“ ermuntere. ${ }^{39}$ Die Übergriffe der ostdeutschen Sicherheitskräfte nahmen jedoch ein Ende.

34 Document 02941, Crisis Over Berlin. American Policy Concerning the Soviet Threats to Berlin, November 1958-December 1962. Part VI: June-September 1961, Research Project No. 614-F, April 1970, Department of State (Documents from the National Security Archive, microfiches published by Chadwyck-Healey Inc.), S. 91 f., 94-96, 98; R. Reeves, a.a.O., S. 212-225; J. E. Smith, Lucius Clay, a.a.O., S. 639-655; W. R. Smyser, From Yalta to Berlin. The Cold War Struggle Over Germany, Houndmills-London 1999, S. 162-167; C. Münger, a.a.O., S. 105 f.

35 Document 02941, Crisis Over Berlin. American Policy Concerning the Soviet Threats to Berlin, November 1958-December 1962. Part VI: June-September 1961, Research Project No. 614-F, April 1970, Department of State (Documents from the National Security Archive, microfiches published by Chadwyck-Healey Inc.), S. 97 f.; Generalmajor A. Watson an Oberst A. V. Solov'ëv, 15. 8. 1961, SAPMO-BArch, DY 30/3691, Bl. 63 f. (russ. Übers.).

36 Niederschrift der Unterredung zwischen Oberst A.V. Solov’ëv und Divisionsgeneral J. Lacombe, 6. 9. 1961, SAPMO-BArch, DY 30/3691, Bl. 77-87 (russ.), 65-76 (dte. Übers.); M. Pervuchin an I. I. Il'ičëv, 6. 10. 1961, AVPRF, 0742, 6, 17, 4, Bl. $118 \mathrm{f}$.

37 Bruce W. Menning, The Berlin Crisis of 1961 from the Perspective of the Soviet General Staff, in: William W. Epley (Hrsg.), International Cold War Military Records and History. Proceedings of the International Conference on Cold War Military Records and History Held in Washington, D.C., 21-26 March 1994, Washington, D.C., 1996, S. 56.

38 J. E. Smith, Lucius Clay, a.a.O., S. 655 f.

39 So der sowjetische Stadtkommandant, Oberst Solov'ëv, zum amerikanischen Stadtkommandanten, General Watson, am 26. 9. 1961, lt. M. Pervuchin an A. A. Gromyko, 26. 8. 1961, AVPRF, 0742, 6, 17, 4, B1. 97. In gleichem Sinne äußerte er sich Anfang September gegenüber dem französischen Stadtkommandanten: M. Pervuchin an V. S. Smirnov, 5. 9. 1961, AVPRF, 0742, 6, 17, 4, B1. 100-103. 
Für die Westmächte hatte die Unantastbarkeit der Wege nach West-Berlin über DDR-Territorium zentrale Bedeutung. ${ }^{40}$ Die Regierung der UdSSR suchte diese nach wie vor in Frage zu stellen. Am 23. August sandte sie ihnen eine Note mit der Aufforderung, den „illegalen und provokativen Aktivitäten“ der Bundesrepublik in West-Berlin ein Ende zu setzen. Der Angriff richtete sich jedoch weniger gegen die westdeutschen Bindungen der Stadt als gegen den unkontrollierten Flugverkehr. Die Luftkorridore würden in flagranter Verletzung des geschlossenen Abkommens zur Beförderung von „Revanchisten, Extremisten, Saboteuren und Spionen“ mißbraucht. Die Überflugrechte waren demnach den westlichen Staaten von der UdSSR nur zeitweilig zugestanden worden, „um die Erfordernisse ihrer Garnisonen [in West-Berlin] zu befriedigen, nicht für die subversiven und revanchistischen Zwecke des westdeutschen Militarismus.“ Das Verlangen, Bonner Amtspersonen dürfen die westlichen Flugzeuge nicht benutzen, weil ihr Aufenthalt und ihre „Einmischung“ in West-Berlin unakzeptabel seien, lief darauf hinaus, daß die Westmächte von den Luftwegen nur so weit Gebrauch machen könnten, wie die UdSSR das erlaubte. ${ }^{41}$

Demnach gab es generell kein eigenständiges westliches Recht auf Flugverkehr nach und von West-Berlin. Es war folglich legitim, wenn die Sowjetunion ihnen bei Abschluß des Friedensvertrags dieses Recht entzog. Diese Behauptung konnten die drei Regierungen nicht ohne Einspruch lassen. Sie wiesen die Note mit Nachdruck zurück und bekräftigten, daß sie die Luftkorridore aufgrund originären Rechts benutzten. Auf dieser Grundlage seien der militärische und zivile Flugverkehr völlig rechtmäßig. Die USA sprachen in einer scharfen Erklärung von einer „kaum verhüllten Aggressionsdrohung“ gegen die westlichen Flugrouten und warnten die UdSSR und die DDR, jedes Vorgehen gegen den freien Zugang nach West-Berlin werde als „aggressiver Akt“ angesehen werden. ${ }^{42}$ Moskau erwiderte, daß Flüge mit „Revanchisten, Militaristen, Spionen und Saboteuren“, die gegen die DDR tätig seien, nicht geduldet werden könnten. Es gebe keinen Vier-Mächte-Beschluß über einen unkontrollierten kommerziellen Flugtransport von Personen, die nicht im Dienst der westlichen Besatzungsbehörden stünden. ${ }^{43}$ Demnach war der zivile Luftverkehr, der den West-Berlinern und Westdeutschen den einzig unkontrollierten Zugang bot, bereits vor Abschluß des Friedensvertrags rechtswidrig und hinfällig.

Wenig später inszenierte die DDR auf der Autobahn zwischen Berlin und Helmstedt Aktionen gegen den militärischen Transit, der die rechtliche Basis für den zivilen West-Berlin-Verkehr bildete. Die Volkspolizei hielt am 21. September zwei US-Soldaten sechs Stunden lang fest. Am folgenden Tag wurde ein Sergeant

40 Vgl. dazu die internen Überlegungen in Washington, erwähnt bei D. Mußgnug, a.a.O., S. 169.

41 Note der UdSSR an die USA, 23. 8. 1961, in: Documents on Germany, a.a.O., S. 783 f.; Document 02941, Crisis Over Berlin. American Policy Concerning the Soviet Threats to Berlin, November 1958-December 1962. Part VI: June-September 1961, Research Project No. 614-F, April 1970, Department of State (Documents from the National Security Archive, microfiches published by Chadwyck-Healey Inc.), S. 101.

42 Ebd., S. 101 f.; Note der USA an die UdSSR, 26. 8. 1961, in: Documents on Germany, a.a.O., S. 785 f.; Stellungnahme des State Department, 1. 9. 1961, ebd., S. 787 f.

43 Note der UdSSR an die USA, 2. 9. 1961, ebd., S. 788 f. Die Notenkontroverse wurde danach weiter fortgesetzt, siehe Note der USA an die UdSSR, 8. 9. 1961, ebd., S. 789-793; Note der UdSSR an die USA, 17. 9. 1961, ebd., S. 793-795. 
mit seiner Familie ebenfalls angehalten und anschließend zurückgeschickt. Als sich der amerikanische Stadtkommandant darüber bei der sowjetischen Seite beschwerte, rechtfertigte diese das Vorgehen mit dem Hinweis, das militärische Personal der USA mißachte ostdeutsche Verkehrszeichen. ${ }^{44}$ Clay ließ daraufhin Militärpolizeistreifen in voller Uniform die Autobahn auf- und abfahren. Sie waren mit Funkgeräten ausgerüstet und sollten in Not geratenen Truppen bei Bedarf „technische Hilfe“ leisten. Die sowjetische Seite protestierte gegen die Patrouillen, ergriff aber keine Gegenmaßnahmen. Als keine weiteren Behinderungen stattfanden, stellte Clay die Fahrten am 30. Oktober ein. ${ }^{45}$ Anscheinend wollte der Kreml testen, wie die Amerikaner reagierten, wenn die DDR-Behörden ihnen zugedachte Kontrollrechte auf den West-Berliner Zugangswegen schon vor Abschluß des Friedensvertrages in Anspruch nahmen.

Noch vor der abschließenden Auseinandersetzung um Friedensvertrag und Freistadtregelung suchte Ulbricht die Kontrolle der DDR über den Flugverkehr zwischen West-Berlin und der Bundesrepublik durchzusetzen. Wenn die VierMächte-Rechte in dieser entscheidenden Frage beseitigt wurden, waren die Voraussetzungen für den östlichen Sieg in Berlin geschaffen. Der SED-Chef machte Mitte September bei Chruschtschow geltend, daß die „Frage der Flugverbindungen über das Hoheitsgebiet der DDR“ zentrale Bedeutung habe. ${ }^{46}$ Nachdem der Termin für den Abschluß des Friedensvertrages aufgehoben worden war, verlangte er Ende Oktober vom sowjetischen Parteichef, der Kampf um die Anerkennung der ostdeutschen Souveränität müsse allmählich gesteigert werden, bis zuletzt der Vertreter der UdSSR seinen Auszug aus der Alliierten Luftsicherheitszentrale erkläre und damit deren Tätigkeit beende. Die Westmächte würden dann genötigt sein, sich an die Flugsicherheitsbehörde der DDR zu wenden, d.h. deren Kontrolle über den Luftverkehr zwischen West-Berlin und der Bundesrepublik grundsätzlich zu akzeptieren. ${ }^{47}$ Das lief praktisch auf die Forderung hinaus, die Konfrontation mit den Westmächten bereits vor Abschluß des Friedensvertrages einzuleiten. Daran hatte der Kreml kein Interesse.

\section{Konflikte um den Status von Ost-Berlin}

Ulbricht bemühte sich bald nach der Abriegelung West-Berlins um die Beseitigung des Vier-Mächte-Status von Ost-Berlin. Er wollte das Zutrittsrecht der Westmächte aufgehoben sehen, um die uneingeschränkte Souveränität über die „Hauptstadt der DDR“ zu demonstrieren. Deshalb suchte er die Kontrolle über die Abfertigungsmodalitäten an der Sektorengrenze auch in Bezug auf westliche Beamte und Militärpersonen in ostdeutsche Hand zu bringen. Chruschtschow war davon überzeugt, daß Washington nur West-Berlin im Auge habe und allein durch Prestigebedürfnis daran gehindert werde, auf das Zutrittsrecht zum Ostteil

44 M. Pervuchin an I.I. Il'ičëv, 26. 9. 1961, AVPRF, 0742, 6, 17, 4, Bl. 111-114.

45 B. W. Menning, a.a.O., S. 57.

46 W. Ulbricht an N. S. Chruščëv, 16. 9. 1961, SAPMO-BArch, DY 30/3509, Bl. 102.

47 W. Ulbricht an N. S. Chruščëv, 30. 10. 1961, SAPMO-BArch, NY 4182/1206, Bl. 38 f. 
der Stadt offen zu verzichten. ${ }^{48}$ Daher hatte die sowjetische Militärführung kein grundsätzliches Bedenken, den DDR-Behörden die Zuständigkeit für die Kontrolle aller Personen, also auch der amtlichen Vertreter der Westmächte, beim Betreten Ost-Berlins zuzubilligen. Die westliche Seite sollte aber vor Zustandekommen der Freistadtregelung nicht unnötig herausgefordert werden, zumal der Kreml die Infragestellung seines - bis dahin bestehenden - Rechts auf Zutritt zu West-Berlin vermeiden wollte. Deswegen erkannte die UdSSR die Souveränität der DDR in der Zutrittsfrage zunächst nur grundsätzlich an. Solange die Westmächte noch in Berlin präsent waren, hatten daher deren Amtspersonen dem Prinzip der ostdeutschen Zuständigkeit nur durch Vorzeigen ihrer Ausweispapiere formale Achtung zu erweisen. ${ }^{49}$

Die amerikanische Seite, vor allem General Clay, war der Ansicht, diese Abfertigungsmodalität könne als Ausdruck ostdeutschen Rechts auf Kontrolle nicht hingenommen werden, weil der Vier-Mächte-Status Gesamt-Berlins auf dem Spiel stehe. Nur die UdSSR komme als Gegenüber in Ost-Berlin-Fragen in Betracht. Wenn die DDR auf dem neuen Verfahren bestehe, gefährde sie damit den sowjetischen Zutritt zu den Westsektoren. Darauf wollte der Kreml nicht verzichten. Trotzdem wies er den Protest mit dem Hinweis zurück, es handele sich um eine innere Angelegenheit der DDR, in die sich die UdSSR nicht einmische. ${ }^{50}$ Faktisch jedoch achtete man in Moskau nach wie vor darauf, daß Ulbricht sich in den Grenzen dessen hielt, was mit dem sowjetischen Interesse am Zutritt zu WestBerlin noch vereinbar war. Solange der SED-Chef nicht mehr als das bloße Vorzeigen von Ausweisen forderte, galt es als unwahrscheinlich, daß die Amerikaner ihren Sektor für sowjetische Amtspersonen sperren würden, denn dann hatten sie ihrerseits mit dem Ausschluß aus Ost-Berlin zu rechnen.

In den folgenden Wochen hielt der sowjetische Stadtkommandant weisungsgemäß daran fest, daß die UdSSR mit den Fragen des Regimes an der Sektorengrenze nichts zu tun habe. Die DDR habe darüber entschieden, und die sowjetische Seite könne nicht darüber befinden. Mit der Begründung wies er auch das Ersuchen um Vermittlungsdienste ab. Man solle sich direkt mit den zuständigen ostdeutschen Stellen in Verbindung setzen. ${ }^{51}$ Der Konflikt spitzte sich zu, als die DDR am 23. August mit dem Hinweis auf ihre souveränen Rechte den Zutritt westlicher Militärs und Amtspersonen auf einen einzigen Übergang, den seither so genannten „Checkpoint Charlie“, beschränkte.52 Intern erhob die sowjetische Seite durch ihren Botschafter in Ost-Berlin unter Hinweis auf die Vier-MächteBeschlüsse Einspruch, doch blieb dies ohne Wirkung. ${ }^{53}$ Als sich der US-Stadt-

48 Die Westmächte sahen sich mit der Erwartung konfrontiert, daß sie es akzeptieren würden, wenn die UdSSR jede Vier-Mächte-Verantwortung hinsichtlich Ost-Berlins in Abrede stellte und sie in allen diesbezüglichen Angelegenheiten auf die Zuständigkeit der DDR-Regierung verwies (J. C. Ausland, a.a.O., S. 64).

49 Anatoli Gribkow, Der Warschauer Pakt. Geschichte und Hintergründe des östlichen Militärbündnisses, Berlin 1995, S. 138 f.; Dorothee Mußgnug, Alliierte Militärmissionen in Deutschlands 1946-1990, Berlin 2001, S. 168.

50 Bezugnahme darauf bei M. Pervuchin an A. A. Gromyko, 26. 8. 1961, AVPRF, 0742, 6, 17, 4, B1. 95.

51 B. W. Menning, a.a.O., S. 55 f.

52 G. Kunze, a.a.O., S. 41.

53 Erwähnt im Schreiben von W. Ulbricht an N. S. Chruščëv, 30. 10. 1961, SAPMO-BArch, NY 4182/1206, Bl. 32 f. 
kommandant der USA gegen die Verletzung des Vier-Mächte-Status durch die „weiteren unrechtmäßigen Beschlüsse“ der DDR wandte und die UdSSR dafür verantwortlich machte, wurde das zurückgewiesen. Das Vorgehen der DDR sei „völlig rechtmäßig“. Das amerikanische Personal müsse sich ebenso wie die sowjetische Seite den ostdeutschen Anordnungen fügen. In gleicher Weise wurde die Beschwerde nicht akzeptiert, die Volkspolizei habe rechtswidrig einen Bus der Militärpolizei angehalten, die Identifikation der Insassen verlangt und erst nach langem Hin und Her den Grenzübertritt erlaubt. Nach Ansicht der USA waren derartige Beschränkungen des Rechts auf ungehinderten Zutritt zum sowjetischen Sektor nicht hinzunehmen. ${ }^{54}$ Im Oktober suchte General Clay den Zutritt außerhalb des Checkpoints Charlie zu erzwingen, scheiterte aber, weil die Volkspolizei von der Schußwaffe Gebrauch machte. ${ }^{55}$ Das trug dem SED-Regime intern scharfen sowjetischen Tadel ein. ${ }^{56}$ Der Kreml hielt die Anwendung von Gewalt gegen Vertreter westlicher Staaten für riskant.

Nach außen hin wahrte die UdSSR den Anschein vollen Einvernehmens mit der DDR. Clays generell entschlossenes Eintreten für die westlichen Interessen ${ }^{57}$ zeigte gleichwohl Wirkung. Die ostdeutsche Polizei ließ das amerikanische Zivilpersonal nach Ost-Berlin passieren, ohne die Vorlage der Ausweise zu fordern. ${ }^{58}$ Ulbricht wollte sich freilich damit nicht abfinden. In einem Brief an Chruschtschow beklagte er, daß die westlichen Stadtkommandanten „durch verschiedene Proteste in der Öffentlichkeit den Eindruck zu erwecken“ suchten, „daß ein Viermächte-Status in Berlin noch existiert“, und verlangte, daß „solche Beschwerden [von sowjetischer Seite] überhaupt nicht mehr angenommen " werden dürften.59 Am 20. September teilte er Perwuchin seine Absicht mit, Visa für ausländische Besucher Ost-Berlins einzuführen, ohne daß er eine Ausnahme für die westlichen Diplomaten vorsah, und äußerte die Erwartung, es werde aufgrund der Unterstützung der UdSSR für das Verlangen der DDR nach voller Souveränität keine Bedenken dagegen geben. Der Botschafter stimmte zwar grundsätzlich zu, erklärte aber, der jetzige Moment sei „ungeeignet für die Einleitung weiterer Kontrollmaßnahmen an der Grenze zu West-Berlin“. Der geplante Schritt könne „eine unnötige Komplikation der Lage hervorrufen“ und die sowjetische „Position in Zusammenhang mit den in Gang kommenden Verhandlungen zwischen UdSSR und USA erschweren“. .60

Chruschtschow hakte nach mit der Aufforderung, ihm keine Schwierigkeiten zu bereiten. Nach der Sicherung der Grenzen zu West-Berlin und angesichts bevorstehender Verhandlungen mit den USA sollten alle „Schritte vermieden werden, die die Situation verschärfen könnten, besonders in Berlin." Vor allem sei „angebracht, sich neuer Maßnahmen zu enthalten, die die von der Regierung der

54 M. Pervuchin an A. A. Gromyko, 26. 8. 1961, AVPRF, 0742, 6, 17, 4, Bl. 95-97. Ähnlich im Gespräch mit dem französischen Stadtkommandanten: M. Pervuchin an V. S. Smirnov, 5. 9. 1961, AVPRF, 0742, 6, 17, 4, Bl. 100-103.

55 B. W. Menning, a.a.O., S. $54 \mathrm{f}$.

56 Ebd., S. 56.

57 Hierzu näher J. E. Smith, Lucius Clay, a.a.O., S. 654-658; W. R. Smyser, a.a.O., S. 168-170.

58 N. S. Chruščëv an W. Ulbricht, 28. 9. 1961, SAPMO-BArch, DY 30/3509, Bl. 106.

59 W. Ulbricht an N. S. Chruščëv, 16. 9. 1961, SAPMO-BArch, DY 30/3509, Bl. 103.

60 B. W. Menning, a.a.O., S. 58. 
DDR errichtete Kontrollordnung an der Grenze mit Westberlin verändern würden." 61 Ulbricht dachte weiter daran, den westlichen Diplomaten den freien Zutritt zu Ost-Berlin zu verwehren. Der Kreml ließ dies nicht zu mit dem Argument, dann würden die Westmächte den sowjetischen Besuchen in West-Berlin Hindernisse in den Weg legen.62 Gleichwohl bestand der SED-Chef in einem Gespräch mit Mikojan am 7. Oktober unbeirrt darauf, er müsse über den westlichen Zutritt zur „Hauptstadt der DDR“ uneingeschränkt entscheiden. Die Bewegungsfreiheit der Amerikaner in Ost-Berlin wirke auf die Bevölkerung demoralisierend und lasse sie an der Durchsetzungsfähigkeit sozialistischer Macht zweifeln. Die DDR werde die Verletzung ihrer Souveränität durch die USA nicht mehr lange hinnehmen, wolle aber während der laufenden Verhandlungen zwischen ihnen und der UdSSR zunächst auf Maßnahmen verzichten. In Moskau war man beunruhigt. Am 19. Oktober empfahlen der Außen- und der Verteidigungsminister dem Kremlchef in einer gemeinsamen Stellungnahme, Ulbricht zu empfehlen, keine neuen Schritte ohne vorherige Erörterung mit der sowjetischen Seite zu unternehmen. Er solle ihn davon in Kenntnis setzen, daß die Amerikaner nach vorliegenden Informationen es darauf abgesehen hätten, möglichst viele Zwischenfälle mit der Volkspolizei zu provozieren. Daher müsse diese zu Zurückhaltung angehalten werden. Zudem erhielt Chruschtschow den Rat, zwecks Konfliktverhütung an der Grenze zu West-Berlin mit Funkgeräten ausgerüstete sowjetische Offiziere patrouillieren zu lassen. Bei Vorkommnissen, bei denen Militärpersonal der Westmächte beteiligt sei, sollten sie das Oberkommando sofort unterrichten, das dann rasch eine Untersuchung des Vorfalls vor Ort zu veranlassen habe. ${ }^{63}$

\section{Zuspitzung des Konflikts}

Clay zog aus der auffallenden Zurückhaltung der DDR an der Sektorengrenze den Schluß, der Kreml wolle es nicht auf einen militärischen Konflikt ankommen lassen. Durch entschlossenes Vorgehen könne man ihn dazu bringen, für die uneingeschränkte Respektierung der westlichen Rechte zu sorgen. Er wollte Chruschtschow die Möglichkeit nehmen, sich weiter hinter der - vorgeblich in voller Unabhängigkeit entscheidenden - DDR zu verstecken und seine Verantwortung für deren Handeln in Abrede zu stellen. Anders als Kennedys Ratgeber war er davon überzeugt, das Risiko einer militärischen Eskalation werde den sowjetischen Führer verunsichern und im gewünschten Sinne beeinflussen. Unter dem Eindruck drohender Kriegsgefahr werde dieser nicht tatenlos zusehen, wie Ulbricht den Westen herausfordere, und ihn zügeln, um einem bewaffneten Konflikt zu entgehen. Clay besaß das Vertrauen des Präsidenten und erhielt dessen Billigung. ${ }^{64}$ Kennedy war überzeugt, der Ruf uneingeschränkter Entschlossenheit

61 N. S. Chruščëv an W. Ulbricht, 28. 9. 1961, SAPMO-BArch, DY 30/3509, Bl. 106.

62 Gespräch M. G. Pervuchin - Honecker, 3. 10. 1961, RGANI, 5, 49, 376 (rolik 8978), Bl. 120 f.

63 B. W. Menning, a.a.O., S. 59.

64 Telegram From the Department of State to the Mission in Berlin, 18. 10. 1961, in: Foreign Relations of the United States (FRUS) 1961-1963, Bd. XIV: Berlin Crisis 1961-1962, Washington 1993, S. 508 f.; Letter From the President's Special Representative in Berlin to President Kennedy, 18. 10. 
zur Verteidigung der eigenen Rechte sei für die künftigen Verhandlungen mit der UdSSR äußerst wichtig. ${ }^{65}$

Am 22. Oktober wollte ein hoher Beamter der USA den Checkpoint Charlie passieren. Als ihn die DDR-Polizei anhielt, verweigerte er das Vorzeigen des Ausweises und wurde daraufhin nicht durchgelassen. Der ostdeutsche Posten war auch nicht bereit, gemäß früherer Praxis einen Vertreter der UdSSR herbeizurufen. Clay reagierte mit der Entsendung eines Trupps Soldaten. Als die Durchfahrt auch dann noch nicht freigegeben wurde, begleiteten die Soldaten das Fahrzeug über die Sektorengrenze, ohne auf Widerstand zu stoßen. Ein Offizier der östlichen Besatzungsmacht erklärte danach den Amerikanern, die vorangegangene Zurückweisung sei ein Fehler gewesen. Am Abend konnte der Übergang ohne Schwierigkeiten benutzt werden. ${ }^{66}$ Die militärische Eskorte, mit der die USA ihren Zivilbediensteten den Zutritt ermöglichten, ließ den Kreml eine Verschärfung der Situation befürchten, die den Westmächten gegen die angestrebten Verhandlungen über den Friedensvertrag gerichtete „Provokationen“ erleichtere. Moskauer Mißmut über das eigenmächtige ostdeutsche Vorgehen verhinderte nicht, $\mathrm{daß}$ das DDR-Innenministerium am 24. Oktober eine Verordnung erließ, die den Konflikt um den Zutritt nach Ost-Berlin anheizte. Es war von zunehmenden, in „provokatorischer“ Form erfolgenden „Verletzungen der staatlichen Ordnung am Grenzkontrollpunkt Friedrichstraße durch Angehörige der USA-Besatzungsmacht" und von zahlreichen amerikanischen Übergriffen und Willkürakten die Rede. Der „angebliche“ Chef der Militärpolizei habe als angetrunkener Rowdy einen Polizisten angefahren und krankenhausreif gemacht. Zur Verhinderung solcher Vorkommnisse seien die Sicherheitsorgane angewiesen worden, ausländische Staatsbürger nur „nach Vorweisen ihres Passes passieren zu lassen.“67

Clay nahm weder Maßnahme noch Beschuldigung hin. Aus seiner Sicht kam es darauf an, die UdSSR zur Anerkenntnis ihrer Verantwortung für das ostdeutsche Vorgehen zu nötigen. Er schickte zwei Soldaten in Zivil an den Checkpoint Charlie, wo ihnen aufgrund der DDR-Verordnung die Durchfahrt verweigert wurde. Der herbeigerufene hochrangige Vertreter der Sowjetunion erklärte das für rechtens. Obwohl Chruschtschow von den Ministern des Auwärtigen und der Verteidigung geraten worden war, Ulbricht zum Verzicht auf Maßnahmen zu bewegen, die den „Erfordernissen des Augenblicks“ nicht entsprächen, ${ }^{68}$ hielt er es für richtig, sich gegenüber den Amerikanern hinter den SED-Chef zu stellen. ${ }^{69}$ Gromyko mußte sogar beim Botschafter der USA in Moskau Beschwerde darüber führen, $\mathrm{daß}$ „unbekannte Personen in Zivil“ versucht hätten, mit einem amerikanischen Fahrzeug in Ost-Berlin einzudringen, ohne gemäß bestehender Ordnung einen

1961, ebd., S. 509-513; Telegram From the Department of State to the Mission in Berlin, 3. 11. 1961, ebd., S. 553 f. Vgl. W. R. Smyser, a.a.O., S. 170 f.

65 J. E. Smith, Lucius Clay, a.a.O., S. 642f., 651-654.

66 E. Lightner an Department of State, 23. 10. 1961, in: FRUS 1961-1963, XIV, S. $524 \mathrm{f}$.

67 Mitteilung des Ministeriums des Innern zur wachsenden Zahl von Grenzverletzungen, in: Neues Deutschland, 24. 10. 1961.

68 B. W. Menning, a.a.O., S. $59 \mathrm{f}$.

69 V. M. Zubok, Khrushchev's Motives, a.a.O., S. 27 f. 
Ausweis zu zeigen. ${ }^{70}$ Clay hielt es zwar grundsätzlich für kein Unglück, wenn sich zivile Repräsentanten der Westmächte ausweisen mußten, meinte aber, man dürfe nicht unter Druck eine neue Praxis akzeptieren, die für die DDR nur der erste Schritt zur Aufhebung der westlichen Rechte in Ost-Berlin insgesamt sei. ${ }^{71}$

\section{Konfrontation am Checkpoint Charlie}

Der amerikanische General ging davon aus, die sowjetische Führung werde die Dinge nicht laufen lassen, wenn sie das Entstehen eines militärischen Konflikts befürchte. Daher suchte er im Kreml den Eindruck zu erwecken, als wollten es die USA auf eine bewaffnete Auseinandersetzung ankommen lassen. Er ließ am Checkpoint Charlie zehn Panzer auffahren, die teilweise mit Räumgerät ausgestattet waren und mithin den Auftrag zu haben schienen, die Hindernisse auf dem Weg in den Sowjetsektor gewaltsam zu beseitigen. Dann schickte er eine Eskorte, die ein aufgehaltenes Fahrzeug über die Grenze hin- und wieder zurückgeleitete. Am folgenden Nachmittag wiederholte er die Aktion. Nachdem der amerikanische Wagen seine Fahrt in den Ostsektor beendet hatte, rückten die Panzer näher an den Übergang heran. Wie vorausgesehen, fürchtete Chruschtschow, die Grenzsperren sollten entfernt werden. Das wollte er keinesfalls zulassen und darauf notfalls mit Gewalt antworten.72 Auf seinen Befehl hin brachte Marschall Konew einige Häuserblocks entfernt seinerseits Panzer in Stellung. Durch Abdecken der Sowjetsterne suchte er den Eindruck zu erwecken, es handele sich um DDRKräfte, doch ließen sich die Amerikaner nicht täuschen. Nun führte Clay seine Panzer ganz dicht an den Checkpoint heran. Konew sah sich nun ebenfalls genötigt, seine Panzer ganz nahe heranzuholen. ${ }^{73}$ Damit hatte der amerikanische General sein Ziel erreicht: Vor aller Welt war klargestellt, daß die UdSSR, nicht die DDR das östliche Vorgehen in der geteilten Stadt bestimmte. Der Kreml konnte sich nicht länger durch den Hinweis auf das vorgeblich eigenständige Handeln des ostdeutschen Verbündeten aus der Verantwortung stehlen. ${ }^{74}$

70 Erklärung Gromykos gegenüber Thompson, 27. 10. 1961, SAPMO-BArch, DY 30/3509, Bl. 217219. Vgl. Telegram From the Embassy in the Soviet Union to the Department of State, 27. 10. 1961, in: FRUS 1961-1963, XIV, S. 541-543.

71 Telegram From the Mission in Berlin to the Department of State, 24. 10. 1961, ebd., S. 532-534. Clays Vermutung, daß es der SED-Führung entscheidend darauf ankomme, vor Verhandlungsbeginn die westlichen Rechte in Ost-Berlin zu kassieren, wird bestätigt durch das Schreiben Ulbrichts an Chruščëv vom 30. 10. 1961 (SAPMO-BArch, NY 4182/1206, Bl. 32-34, 36-38.

72 V. M. Zubok, Khrushchev's Motives, a.a.O., S. 27 f. In gleichem Sinne die auf Akten der sowjetischen Führung beruhende Angabe von A. A. Fursenko, Kak byla postroena berlinskaja stena, in: Istoričeskie zapiski, 4/2001 (122), S. 81 f., das Auffahren der amerikanischen Panzer am Checkpoint Charlie sei als Einleitung einer militärischen Operation aufgefaßt worden.

73 E. Lightner an Department of State, 24. 10. 1961, in: FRUS 1961-1963, XIV, S. 532-534; Memorandum von F. Kohler für D. Rusk, 24. 10. 1961, in: FRUS 1961-1963, XIV, S. 535; E. Lightner an Department of State, 25. 10. 1961, in: FRUS 1961-1963, XIV, S. 537-539; W. R. Smyser, a.a.O., S. 172-175; J. E. Smith, Lucius Clay, a.a.O., S. 659-661.

74 Editorial Note [über Erklärung von General Clay auf einer Pressekonferenz am 27. 10. 1961], in: FRUS 1961-1963, XIV, S. 544. Vgl. Letter From the President's Special Representative in Berlin to President Kennedy, 18. 10. 1961, ebd., S. 509-513. 
Clays Vorgehen ließ Konew befürchten, die Panzerkonfrontation könnte zum Schußwechsel und Krieg führen. Er ersuchte daher Chruschtschow um die Weisung zur Deeskalation des Konflikts. Der Kremlchef war ebenfalls nervös 75 und gab ohne weiteres den erbetenen Befehl. Der sowjetische Marschall zog daraufhin seine Panzer ein kleines Stück zurück. ${ }^{76}$ Clay folgte dem Beispiel. Beide Seiten rückten schrittweise auseinander, bis der Schauplatz völlig geräumt war. ${ }^{77} \mathrm{Ob}-$ wohl die akute Spannung damit vorüber war, blieb der Kremlchef weiterhin besorgt. Als erstes verstärkte er die Kontrolle über das Vorgehen der DDR. ${ }^{78}$ Ulbricht, der gerade in Moskau weilte, erhielt überdies den Hinweis, es sei nicht „Zweckmäßig“, der Auseinandersetzung über den Zutritt der westlichen Amtspersonen Aufmerksamkeit in der Presse zu widmen. Von „übertriebener“ Polemik sei Abstand zu nehmen; nur vom prinzipiellen Recht der DDR zu Kontrollen an der Grenze zu West-Berlin dürfe die Rede sein. Der SED-Chef versicherte seinen Leuten, die UdSSR trete trotzdem voll für eine Überwachung der Grenze durch die Volkspolizei ein. Es werde die „Lösung noch anderer Probleme“ vorbereitet, doch sei im Augenblick Zurückhaltung geboten, „damit uns andere Maßnahmen nicht unnötig erschwert werden." 79

Chruschtschow wandte sich über einen Mittelsmann an Kennedy, um ihn vom Erfordernis einer Entspannung des wechselseitigen Verhältnisses zu überzeugen. ${ }^{80}$ Der Präsident antwortete, auch er wolle die Beziehungen verbessern. Das ließ den sowjetischen Führer fortan vermuten, der amerikanische General habe eigenmächtig gehandelt. ${ }^{81}$ Das traf zwar nicht zu, befestigte aber das Vorurteil des Kremlchefs, es gebe mächtige „aggressive und militaristische Kräfte“ in den USA, die den Präsidenten (den er nach wie vor für schwach hielt) unter Druck setzten. Personen in Kennedys Umgebung, die Clays Vorgehen verurteilten, und Macmillan, der dem Geschehen am Checkpoint Charlie mit blankem Entsetzen zugesehen hatte, bestärkten Chruschtschow in der Meinung, der General habe unautorisiert gehandelt. ${ }^{82}$ Es war daher kein Zufall, daß die DDR-Polizei ab Mitte November wiederholt erneut Ausweiseinsicht verlangte und der sowjetische Stadtkommandant den Protest abwies mit der Begründung, die amerikanische Seite müsse sich damit an die zuständigen DDR-Behörden wenden. ${ }^{83}$

75 N. S. Chruščëv, Vremja, ljudi, vlast', Bd. 4, Moskau 1999, S. 493 f.; Sergej Chruščëv, Nikita Chruščêv. Krizisy i rakety. Vzgljad iznutri, Bd. 2, Moskau 1994, S. 140; Sergej Chruschtschow, Die Geburt einer Supermacht. Ein Buch über meinen Vater, Klitzschen 2003, S. 394-396.

76 Dazu näher Aleksej Adžubej, Te desjat' let, Moskau 1989, S. 238.

77 W. R. Smyser, a.a.O., S. 175 f.

78 V. Zubok, Berlin Crisis, 1958-1962: New Evidence from Soviet Archives, Entwurf für die Konferenz des Cold War International History Project in Moskau, Januar 1993, S. 37.

79 W. Ulbricht (Moskau) an H. Matern, 27. 10. 1961, SAPMO-BArch, DY 30/3291, Bl. 70.

so Hierzu näher Michael R. Beschloss, The Crisis Years. Kennedy and Khrushchev 1960-1963, New York 1991, S. $334 \mathrm{f}$.

81 S. Chruščëv, Krizisy i rakety, a.a.O., S. 140; Aktenvermerk über Gespräch Krolikowski-Žiljakov in Moskau, 19. 1. 1962, PA-MfAA, G-478, Bl. 27.

82 W. S. Smyser, a.a.O., S. 177. Der Glaube, Clay habe sich mit seinem Verhalten in Widerspruch zu den Absichten des Präsidenten gesetzt, der sich ja stets um einen Interessenausgleich mit der UdSSR bemühte, war weit in den - fast durchweg mit dem Vorgehen des Generals nicht einverstandenen - Washingtoner Regierungskreisen verbreitet, vgl. die Darstellung bei J. C. Ausland, a.a.O., S. 29-41.

83 R. Malinovskij/M. Zacharov an das ZK der KPdSU, 22. 11. 1961, RGANI, 5, 30, 368 (rolik 4633), Bl. $63 \mathrm{f}$. 


\section{Wachsende sowjetische Enttäuschung über die Wirtschaftsleistung der DDR}

Durch das Entgegenkommen, zu dem die USA bereit schienen, sah sich Chruschtschow in der Gewißheit bestätigt, daß Verhandlungen die beste Möglichkeit zur Erreichung seiner Ziele böten. ${ }^{4}$ Zudem ließen ihm die ökonomischen Probleme der DDR eine „Pause“ im Kampf um den Friedensvertrag ratsam erscheinen. Wenn man die Konfrontationspolitik wiederaufnehmen wolle, müsse sich die ostdeutsche Wirtschaft zuvor aus der Abhängigkeit von den Lieferungen der Bundesrepublik befreit haben. Für Ulbrichts Einwand, mit Rücksicht auf die Erwartungen der Bevölkerung müsse man das gesteckte Ziel unnachgiebig weiterverfolgen, hatte der sowjetische Führer kein Verständnis. Ob es denn dem SEDChef die Sache erleichten würde, wenn er sich einer Handelsblockade des Westens gegenübersähe? Als der SED-Chef erklärte, er könne den Wirtschaftsplan nicht erfüllen, erhielt er die unwirsche Antwort, dafür könne er nicht Adenauer verantwortlich machen. ${ }^{85}$

Chruschtschows Mißmut über die unzureichende ökonomische Leistung der DDR und der daraus erwachsende Mangel an Standfestigkeit war seitdem ein Dauerthema des Dialogs mit Ulbricht. Der sowjetische Führer wurde ungeduldig, als sich die Erwartung vom Sommer nicht erfüllte, die Sperrung der Sektorengrenze werde eine rasche Lösung der Wirtschaftsprobleme nach sich ziehen. Ende Oktober bat der SED-Chef um Freigabe der Sonderreserve, die der Kreml für den Fall eines westlichen Embargos bei Abschluß des Separatvertrags bereitgestellt hatte. ${ }^{86}$ Chruschtschow reagierte mit Empörung. Er tadelte das kommunistische Regime in Ost-Berlin, weil es die Ökonomie nicht in Ordnung zu bringen vermöge und die UdSSR dauernd mit außergewöhnlichen Hilfeersuchen behellige. Vor diesem Hintergrund war er weniger denn je bereit, Ulbrichts Verlangen nach Abschluß des Separatvertrags zu entsprechen. Die Goldreserve der UdSSR sei nicht dazu da, um für die Folgen einer wirtschaftlichen Blockade des Westens aufzukommen. ${ }^{87}$ Mitte November berichtete die Ost-Berliner Sowjetbotschaft nach Moskau, die DDR habe sich noch immer nicht stabilisiert. ${ }^{8}$ Der Kremlchef bemängelte, weder habe die Umorientierung auf die UdSSR Fortschritte gemacht, noch sei die Abhängigkeit von westdeutschen Lieferungen überwunden. ${ }^{89}$ Anfang 1962 räumte Ulbricht ein, ungeachtet aller politischen Bedenken könne er vorerst

84 Schon in seinen Ausführungen vor dem Plenum des Politischen Konsultativkomitees am 4. 8. 1961 hatte er gegenüber dem drängenden Ulbricht geltend gemacht, daß man zunächst noch einmal versuchen solle, mit dem Westen zu einem Einvernehmen über den Friedensvertrag zu kommen, ehe man sich zur Konfrontation entschließe. Verhandlungen - damals noch als Vier-Mächte-Konferenz gedacht - seien als „vorbereitende Maßnahme“ akzeptabel, welche die bestehende Lage nicht [zum Schlechteren] ändere (Novaja i novejšaja istorija, 2/1999, S. 73). Nach dem damals beschlossenen Maßnahmeplan war dafür allerdings nur ein Monat, der September 1961, vorgesehen.

85 A. A. Fursenko, a.a.O., S. 85. Vgl. W. Ulbricht an N. S. Chruščëv, 16. 9. 1961, SAPMO-BArch, DY 30/3509, Bl. 103.

86 W. Ulbricht an N. S. Chruščëv, 30. 10. 1961, SAPMO-BArch, NY 4182/1206, Bl. 41-44.

87 A. A. Fursenko, a.a.O., S. 85 f.

88 V. M. Zubok, Khrushchev's Motives, a.a.O., S. 34.

89 Botschafter Dölling an O. Winzer, 17. 11. 1961, PA-MfAA, G-A 478, Bl. 21 f. 
noch nicht auf den innerdeutschen Handel verzichten. Er hoffe aber, diese Schwäche künftig durch enge ökonomische Verflechtung mit der UdSSR zu überwinden. ${ }^{90}$

\section{Beginnende Berlin-Gespräche mit den USA}

In der Annahme, die Grenzschließung zeige Bereitschaft zur Hinnahme der westlichen Berlin-Präsenz an, glaubte Kennedy schon im August an das Bestehen guter Voraussetzungen für eine Übereinkunft. Chruschtschow halte nicht länger an seinen Maximalzielen fest; die Chance zu einem guten Kompromiß, der bei den Gesprächen in Wien nicht möglich gewesen war, sei nunmehr gegeben. Sobald sich der Schock in West-Berlin gelegt hatte und die Lage damit stabilisiert schien, ergriff der Präsident Anfang September im Einvernehmen mit Macmillan die Initiative zu Verhandlungen mit der UdSSR. Er war entschlossen, sich über die Bedenken in Paris und Bonn hinwegzusetzen. Das war freilich nicht unproblematisch. Wenn Kennedy nicht von vornherein die Einheit der Allianz gefährden und die zwei Hauptmächte auf dem europäischen Kontinent zum Ausscheren, vielleicht sogar zu einem separaten Arrangement mit der Sowjetunion veranlassen wollte, dann mußten er den Eindruck vermeiden, daß er die Berlin-Frage bilateral mit dem Kreml über die Köpfe der Verbündeten hinweg entscheiden wollte. Den Verhandlungen durfte daher nur der Charakter von Sondierungsgepräche beigelegt werden, deren Ergebnis der Billigung durch die Bundesgenossen bedurfte. Der amerikanische Präsident war zu dieser Einschränkung bereit in der Gewißheit, daß eine zwischen den USA und der UdSSR geschlossene Vereinbarung hinterher nicht mehr zu kippen sein werde. ${ }^{91}$

Chruschtschow ging darauf gerne ein in der Überzeugung, daß es sich der Sache nach nicht bloß um einleitende Vorgespräche handeln werde. Ungeachtet aller formellen Vorbehalte, würden die Entscheidungen im Dialog mit den USA bereits faktisch getroffen werden. In anschließenden Vier-Mächte-Verhandlungen würden diese dann lediglich formell bestätigt werden. Aufgrund der Verhältnisse im sozialistischen Lager hielt er es für undenkbar, daß die Verbündeten wesentliche Änderungen an der von der Führungsmacht bereits gebilligten Übereinkunft vornehmen könnten. Er wies Gromyko an, einen bevorstehenden USA-Aufenthalt anläßlich eines Auftritts in der UNO-Vollversammlung zu nutzen, um Näheres über die amerikanische Haltung zu erfahren. Er sollte gegenüber Außenminister Rusk das Interesse der UdSSR an einer Übereinkunft betonen, auf die Wahl einer möglichst hohen Verhandlungsebene dringen sowie auf rasche Ergebnisse und die Hinzuziehung von Vertretern beider deutscher Staaten dringen. Zugleich war klarzustellen, daß ein Vier-Mächte-Abkommen über Deutschland und Berlin insgesamt von vornherein nicht in Betracht kam. Die westlichen Bedenken gegen die geforderte Freistadtregelung sollten durch nachdrückliche Hinweise auf die so-

90 Zapis' besedy tt. M. G. Pervuchina i I. I. Il’ičëva s Pervym Sekretarëm CK SEPG V. Ul'brichtom [9. 1. 1962], RGANI, 5, 49, 480 (rolik 9017), Bl. $12 \mathrm{f}$.

91 Memorandum of Conversation [zwischen den drei westlichen Außenministern], 14. 9. 1961, FRUS 1961-1963, Bd. XIV, S. 405-408; C. Münger, a.a.O., S. 108-114. 
wjetische Bereitschaft ausgeräumt werden, Garantien für den Erhalt der inneren Verhältnisse und die Wahrung der äußeren Unabhängigkeit West-Berlins zu geben. ${ }^{92}$

Der Kreml wollte die Erörterungen auf Friedensvertrag und „Normalisierung“ der Lage in West-Berlin begrenzen. Falls die andere Seite dazu nicht bereit sei, konnte bei Festlegung der Agenda für die abschließenden Verhandlungen auf diesen Punkt verzichtet werden, doch sollte die Diskussion trotzdem nur auf diese beiden Fragen gelenkt werden. Die vorgesehene Hinzuziehung von Vertretern beider deutscher Staaten wurde entsprechend dem Verfahren auf der Genfer Außenministerkonferenz von 1959 vorgesehen. Mit dem drohenden Hinweis, daß die UdSSR andernfalls mit der DDR separat Frieden schließen werde, wollte man die USA zu schneller Entscheidung drängen. Wesentliche sowjetische Zugeständnisse wurden nicht ins Auge gefaßt. Die innere Autonomie West-Berlins und der ungehinderte Zugang sollten wie zuvor nur auf zu vereinbarenden Garantien und Zusagen der Regierungen in Moskau und Ost-Berlin beruhen.

Neu war der Vorschlag, die Westmächte müßten sich nicht unbedingt am Friedensschluß mit beiden deutschen Staaten beteiligen. Eine einvernehmliche Regelung könne auch so aussehen, daß die UdSSR zusammen mit anderen dazu bereiten Ländern den Friedensvertrag mit der DDR unterzeichneten. Es würde genügen, wenn die westlichen Staaten den Vertrag mit Bonn gemeinsam mit der Sowjetunion schlössen, deren Vereinbarungen mit der DDR in aller Form akzeptierten und die deutschen Grenzen als unverrückbar anerkannten. Die USA sollten zudem damit einverstanden sein, daß die zwei deutschen Staaten vertraglich auf Nuklear- und Raketenwaffen zu verzichten hatten und daß ihnen ein Gewaltverbot bei wechselseitigen Konflikten auferlegt wurde. Das zielte darauf ab, die Bundesrepublik zum Verzicht auf das Verlangen nach nationaler Einheit und zur förmlichen Anerkennung des SED-Staates zu zwingen. Damit sollte auch die Blockade aufgehoben werden, welche die Bundesregierung gegen die Aufnahme diplomatischer Beziehungen zu Ost-Berlin durch dritte Staaten verhängt hatte. Kernstück des Forderungskatalogs war die völlige Beseitigung des westlichen Besatzungsregimes und des damit verbundenen Rechts auf Berlin-Präsenz und Berlin- Zugang. Der ostdeutschen Souveränität sollte im Blick auf West-Berlin und seine bisherigen Schutzmächte keine Grenze gesetzt sein. Wenn die Westmächte den Friedensvertrag mit der DDR nicht unterschreiben wollten, sollte das für die Gültigkeit der darin getroffenen Regelungen unerheblich sein.93

Chruschtschow übermittelte Kennedy seinen Standpunkt und hob als großes Entgegenkommen hervor, daß die UdSSR nicht auf der Beteiligung der USA am Friedensvertrag mit der DDR bestehe. Er suchte den Präsidenten davon zu überzeugen, daß die Umwandlung West-Berlins in eine „Freie Stadt“ zusammen mit der sowjetischen Garantie für die Aufrechterhaltung dieses Status die Freiheit, Unabhängigkeit und Entfaltung der dortigen Bevölkerung optimal gewährleisten

92 Direktive für Gespräche der sowjetischen Delegation zur XVI. Sitzung der UNO-Vollversammlung mit D. Rusk, o.D. [2. Septemberhälfte 1961], AVPRF, 0129, 45, 329, 13, Bl. 49-53.

93 Ukazanija k peregovoram SSSR s SŠA, Angliej i Franciej (Entwurf von V. Semënov/S. Lapin/I. Il'ičëv/G. Tunkin für A. Gromyko), 4. 9. 1961, AVPRF, 0742, 6, 46, 36, Bl. 81-91). Die Weisung wurde am 17. 10. 1961 und 4. 11. 1961 ohne wesentliche Änderungen erneuert. 
würde. Damit verband er den alten Vorschlag, daß für eine gewisse Zeit an die Stelle der westlichen Garnison entweder Truppen der Westmächte und der UdSSR oder Kontingente aus neutralen Ländern oder Soldaten westlicher, östlicher und dritter Staaten unter UNO-Flagge treten könnten. Es kam ihm mithin allein darauf an, daß die Besatzungsrechte - das heißt der westliche Anspruch auf Anwesenheit in West-Berlin und auf den damit verbundenen Zugang - durch die Friedensverträge mit beiden deutschen Staaten ihre Geltung verloren. Die DDR sollte auf ihrem Gebiet uneingeschränkte Souveränität ausüben, also den Land- und Luftverkehr zwischen West-Berlin und der Bundesrepublik nach Gutdünken bestimmen. ${ }^{94}$

Rusk gab in den beiden ersten Unterredungen mit Gromyko zu verstehen, daß es den USA vor allem anderen auf die Behauptung der Position in Berlin ankam. Der sowjetische Außenminister hielt demgegenüber an den bisherigen Forderungen fest und ließ nur die angebotenen Formvarianten als akzeptabel gelten. Er betonte, die geforderte Respektierung der ostdeutschen Souveränität werde die Amerikaner weder zur Aufnahme diplomatischer Beziehungen zur DDR noch zum Abschluß eines Friedensvertrags mit ihr verpflichten. Mit dem Bemerken, man wolle „strikteste Garantien für den Zugang“ nach West-Berlin geben, schien er Konzessionen anzudeuten. Dabei vermied er, auf Rusks kategorisches Verlangen nach Anerkennung originärer westlicher Berlin-Rechte irgendwie einzugehen, sondern forderte kategorisch, allen Vereinbarungen müsse das Prinzip der uneingeschränkten DDR-Souveränität zugrunde liegen. Besatzungsbefugnisse waren demnach von vornherein ausgeschlossen. Der amerikanische Außenminister nahm den Anspruch auf volle DDR-Souveränität unwidersprochen hin. Auch unterließ er es, gegen die Charakterisierung West-Berlins als einer „selbständigen unabhängigen Einheit“ Stellung zu nehmen. Er räumte ein, die Lage in der Teilstadt sei „nicht völlig zufriedenstellend“. 95

\section{Moskauer Hoffnungen auf ein Einlenken Washingtons}

Das ließ in Moskau den Eindruck entstehen, daß auch die amerikanische Regierung den Status quo für änderungsbedürftig hielt. Sie werde, so hoffte die sowjetische Führung, über die östlichen Berlin-Forderungen mit sich reden lassen. Das zusätzlich unterbreitete Angebot der USA, Vereinbarungen über Abrüstung und nukleare Nichtverbreitung zu schließen, schien verlockend. Davon erhoffte sich der Kreml vor allem, daß die USA den Westdeutschen jeden Zugang zu Kernwaffen verwehren würden. Hoffnung schöpfte Chruschtschow auch aus McCloys Bemerkung, der Berlin-Verkehr müsse „nicht notwendigerweise auf der Grund-

94 N. S. Chruščëv an J. F. Kennedy, 28. 9. 1961, AVPRF, 0129, 45, 329, 12, Bl. 72-89.

95 Zapis' besedy tov. Gromyko A. A. s Gosudarstvennym sekretarëm SŠA Raskom v N'ju Iorke, 27. 9. 1961, AAN, KC PZPR XI A/79, Bl. 357-370; Zapis' besedy tov. Gromyko A. A. s Gosudarstvennym sekretarëm SŠA Raskom v N'ju Iorke, 30. 9. 1961, AAN, KC PZPR XI A/79, Bl. 371-379; Telegram From the Department of State to the Embassy in France, 28. 9. 1961, ebd., S. 439-441; Telegram From the Department of State to the Embassy in France, 2. 10. 1961, ebd., S. 456-460. 
lage des Besatzungsregimes“ gesichert werden. ${ }^{96}$ Kennedy verstärkte die sowjetischen Erwartungen, als er am 6. Oktober nicht nur Gromyko zum Gespräch empfing, sondern auch die drei „essentials“ seiner Rede vom 25. Juli - westliche Präsenz in West-Berlin, Zugang dorthin und Lebensfähigkeit der Stadt - zu relativieren schien. Die UdSSR, so führte der Präsident aus, spreche von der Freiheit West-Berlins, von garantiertem Zugang, von Respektierung der DDR-Souveränität und der Angelegenheit der Grenzen. Es gehe nun darum, dies zu präzisieren. Dann werde man sehen, welche Gewähr es auf dieser Grundlage für die Fortdauer der westlichen Rechte gebe, und eine genauere Vorstellung davon erhalten, was die sowjetische Seite unter „Freiheit“ und „garantiertem Zugang“ verstehe. ${ }^{97}$ Aus Moskauer Sicht deutete sich damit die Bereitschaft der Amerikaner an, nicht mehr auf der Fortdauer des Besatzungsregimes zu bestehen, sondern gegebenfalls auch vertragliche Zusagen für West-Berlin zu akzeptieren.

Die sowjetische Führung kam zu dem Schluß, die entschiedene Vertretung ihres Standpunkts habe im Westen „nicht den mindesten Schatten eines Zweifels“ daran gelassen, daß sie den Friedensvertrag durchsetzen werde. Die westlichen Regierungen seien zur Unterzeichnung zwar nicht bereit, hätten aber begriffen, daß sie den Abschluß mit der DDR nicht verhindern könnten und daß dieser nicht ohne Folgen für West-Berlin und ihre dortige Position bleiben werde. Daher suchten sie nach einem Ausweg auf der Basis eines Kompromisses, wie sie bei jeder Gelegenheit betonten. Ihre Vorschläge zielten darauf $\mathrm{ab}$, eine Verständigung über die Situation herbeizuführen, die nach Abschluß des Friedensvertrages entstehe. Präsenz und Zugang seien mithin für den Westen die entscheidenden Fragen. Auffälligerweise spreche man nicht mehr vom Besatzungsregime; die USA und Großbritannien seien augenscheinlich bereit, eine andere Rechtsbasis zu akzeptieren. Damit war nach Moskauer Ansicht eine annehmbare Verständigungsgrundlage gegeben. Dahinter stand die Erwartung, daß die vom Kreml angebotenen Garantien und Zusagen zu einer Übereinkunft führen würden, ohne daß man Zugeständnisse in der Sache machen müsse. ${ }^{98}$

\section{Abrücken vom Friedensvertragstermin}

Chruschtschow sah sich durch Zweifel an der ökonomischen Standfestigkeit der DDR im Falle einer Ost-West-Konfrontation und durch die Hoffnung auf amerikanisches Einlenken in der Absicht bestärkt, einen direkten Konflikt mit den USA zu vermeiden. Deshalb war er bereit, ihrem Standpunkt zu entsprechen, daß Verhandlungen unter dem Druck eines Ultimatums nicht in Betracht kämen. Am 19. September gab er gegenüber NATO-Generalsekretär Spaak zu erkennen, er habe „keine besondere Eile“ mit dem Friedensvertrag, wenn man dadurch Zeit für diplomatische Gespräche über die Berlin-Frage gewinne. Die angestrebte Frie-

96 Entwurf des sowjetischen Außenministeriums für ein Schreiben Chruščëvs an J. McCloy, 25. 9. 1961, AVPRF, 0129, 45, 329, 12, Bl. 43.

97 Memorandum of Conversation [Kennedy - Gromyko], 6.10. 1961, FRUS 1961-1963, XIV, S. 468-480, hier S. $468 \mathrm{f}$.

98 Beschluß des ZK der KPdSU, 21. 10. 1961, AVPRF, 0742, 6, 46, Bl. 93-103. 
densregelung sei „an kein bestimmtes Datum gebunden“. Die Lösung der Probleme dürfe jedoch nicht „auf unbestimmte Zeit verschoben“ werden.99 Gromyko bestätigte dem Präsidenten Anfang Oktober, daß die Frist von Ende Dezember kein Hindernis für Verhandlungen sei. Unter ausdrücklicher Berufung auf Chruschtschow erklärte er, es gebe „kein schicksalhaftes Datum“. Es sei nur wichtig, daß die Verhandlungen „in einer möglichst guten Atmosphäre“ stattfänden und zur „besten Lösung“ führten. Natürlich dürften sie nicht künstlich hinausgezögert werden. 100

Auch in der Öffentlichkeit deutete sich an, daß der Kreml nicht länger auf einem festen Termin bestand. Den Bekenntnissen zu Friedensvertrag und Freistadtregelung beim DDR-Gründungstag am 7. Oktober fehlte der bis dahin übliche Hinweis auf den Jahresendtermin. ${ }^{101}$ Zehn Tage später machte Chruschtschow in seinem Rechenschaftsbericht an den XXII. KPdSU-Parteitag endgültig klar, daß er vom Ultimatum abgerückt war. Er betonte zwar, die sowjetische Regierung beharre weiterhin auf der „raschesten Lösung der deutschen Frage“ und sei nicht willens, sie „ewig hinauszuschieben“, fügte aber hinzu: „Wenn die Westmächte Bereitschaft zur Regelung des deutschen Problems zeigen, so wird die Frage der Termine der Unterzeichnung eines deutschen Friedensvertrages nicht solche Bedeutung haben. Wir werden dann nicht darauf bestehen, den Friedensvertrag unbedingt bis zum 31. Dezember 1961 zu unterzeichnen.“ Die Hauptsache sei, daß das Problem der Beseitigung der „Überreste des Zweiten Weltkriegs“ überhaupt gelöst werde. 102

Wie in früheren Jahren scheute Chruschtschow auch diesmal die Konfrontation, als es ernst wurde. Zwar war er im Sommer augenscheinlich willens gewesen, am Jahresende den Friedensvertrag gegebenfalls separat mit der DDR abzuschließen, doch hatte er sich inzwischen anders besonnen. Um den Eindruck des Zurückweichens zu vermeiden, betonte er seine Entschlossenheit, keinerlei Zugeständnisse zu machen. Wie er in der Schlußansprache auf dem Parteitag am 27. Oktober erklärte, wollte er nicht zulassen, daß „Verhandlungen nur um der Verhandlungen willen geführt“ würden. Es müsse um „echte Verhandlungen“ gehen. Daher kam etwas anderes als die geforderte Regelung auf der Basis uneingeschränkter Kontrolle der DDR über die West-Berliner Verkehrswege von vornherein nicht in Betracht. Der in Washington erwogene Plan, für den Zugang nach

99 Erinnerungsbericht von P.-H. Spaak über sein Gespräch mit N. S. Chruščëv am 19. 9. 1961, in: Dokumentation zur Deutschlandpolitik, IV, 7, 1. Hbbd., S. $481 \mathrm{f}$.

100 Memorandum of Conversation [Kennedy - Gromyko], 6.10. 1961, FRUS 1961-1963, XIV, S. $471 \mathrm{f}$.

101 Rede von K. N. Rudnëv auf einer Veranstaltung der „Moskauer Öffentlichkeit“, 5. 10. 1961, in: Pravda, 6. 10. 1961; Glückwunschbotschaft von N. S. Chruščëv und L. I. Brežnev an die DDRFührung, 6. 10. 1961, in: Pravda, 7. 10.1961/Neues Deutschland, 7. 10. 1961; Toast von M. A. Suslov auf dem Empfang der sowjetischen Botschaft in Ost-Berlin, 6. 10. 1961, in: Pravda, 7. 10. 1961; Rede von A. I. Mikojan in Ost-Berlin, 6. 10. 1961, in: Izvestija, 8. 10. 1961/Neues Deutschland, 7. 10. 1961 (auszugsweise auch in: Dokumente zur Deutschlandpolitik, hrsg. vom Bundesministerium für Innerdeutsche Beziehungen, IV. Reihe, Bd. 7, 2. Hbbd., Frankfurt/Main 1976, S. 673676).

102 Text: Pravda, 18. 10. 1961. 
West-Berlin einen Korridor zu schaffen, war nach seinen Worten nichts als der Versuch, die Friedensregelung zu verschleppen. ${ }^{103}$

Als der Kreml auf das Berlin-Ultimatum verzichtete, mehrten sich die öffentlichen Anzeichen für ein wachsendes militärisches Stärkebewußtsein der USA. Hatte Kennedy im Wahlkampf vom Herbst 1960 noch der Eisenhower-Administration die vermeintliche „Raketenlücke“ und damit Versagen im Rüstungswettlauf mit der UdSSR vorgehalten, so schätzte er die Lage mittlerweile ganz anders ein. Auf seine Anregung hin stellte Starjournalist Joseph Alsop am 25. September 1961 in der "Washington Post“ fest, bei einer Neubewertung der strategischen Situation durch die Regierung habe sich bei der Sowjetunion ein erheblicher Rückstand der nuklearen Fäuhigkeit gezeigt. ${ }^{104}$ Der stellvertretende amerikanische Verteidigungsminister Gilpatric erklärte am 21. Oktober, die USA hätten bei den strategischen Kernwaffen einen so großen Vorsprung, daß sie sogar nach einem sowjetischen Erstschlag die Überlegenheit behalten würden. ${ }^{105}$ Der Anspruch des Kreml auf militärische Überlegenheit war unhaltbar. Die Hoffnung auf Einschüchterung des amerikanischen Widersachers war Illusion. Vielmehr sahen sich die Vereinigten Staaten in der besseren Position.

Damit war das sowjetische Kalkül in Frage gestellt, Washington mittels Druck zum Eingehen auf die Berlin-Forderungen zu veranlassen. Der Kreml suchte Gilpatrics Aussage vergeblich durch eine Erklärung von Verteidigungsminister Malinowskij zu entkräften, die amerikanischen Berechnungen seien fehlerhaft und Washingtoner Drohungen hätten keinen Einfluß auf die Politik der UdSSR. ${ }^{106}$ Vor diesem Hintergrund verfehlte die seit Juli vorbereitete, am 30. Oktober durchgeführte Zündung einer 50-Megatonnen-Superbombe ${ }^{107}$ die beabsichtigte Drohwirkung. Chruschtschow wußte, daß, wie der amerikanischen Führung durch ihren Informanten Oberst Penkowskij ebenfalls bekannt war, die sowjetischen Streitkräfte aufgrund des Standes ihrer Vorbereitungen keinen großen Krieg gegen den Westen führen konnten. ${ }^{108}$ Mit dem angedrohten Abschluß des separaten Friedensvertrags mit der DDR verband sich daher vollends ein unkalkulierbares Risiko.

\section{Meinungsaustausch mit der SED-Führung}

Ulbricht sah durch den Rückzieher Chruschtschows den lang gehegten Argwohn bestätigt, daß der Kremlchef untätig blieb, wenn es mit dem Abschluß des zuge-

103 Text: Pravda, 28. 10. 1961.

104 Biermann, John F. Kennedy, a.a.O., S. 146.

105 J. C. Ausland, a.a.O., S. 14; Harald Biermann, Die Kuba-Krise: Höhepunkt oder Pause im Kalten Krieg? in: Historische Zeitschrift, Bd. 273 (2001), S. 638.

106 Rede von Marschall Malinovskij auf dem XXII. KPdSU-Parteitag, 24. 10. 1961, in: Pravda, 25. 10. 1961.

107 H. Biermann, a.a.O., S. 639, hält die Explosion für eine Reaktion auf die Erklärung Gilpatrics. Auch wenn nichts über die vorangegangene Beratung Chruščëvs mit den sowjetischen Nuklearexperten am 10. 7. 1961 bekannt wäre, könnte das nicht zutreffen, weil die technischen und organisatorischen Vorbereitungen ungleich mehr Zeit beanspruchten.

108 Jerrold Schecter/Peter Deriabin, The Spy Who Saved the World. How a Soviet Colonel Changed the Course of the Cold War, New York 1992, S. 205-213. 
sagten Separatvertrags ernst wurde. Da er daran nichts ändern konnte, suchte er den Schaden wenigstens zu begrenzen. In einem Schreiben vom 30. Oktober suchte er den sowjetischen Führer auf einen nur kurzen Aufschub der geplanten Vorbereitungsschritte für den Friedensvertrag festzulegen. Nach seiner Ansicht sollten die Außenminister der Warschauer-Pakt-Staaten statt, wie im August vorgesehen, Ende November nunmehr Anfang Dezember miteinander konferieren und dann den Text des Friedensvertrages und der Folgevereinbarungen zwar nicht abschließend formulieren, wie damals beschlossen worden war, wohl aber einer Kommission zur endgültigen Ausarbeitung überweisen. Die DDR hatte sich mit 24 detaillierten Entwurfstexten und Themenpapieren ${ }^{109}$ auf alle Probleme intensiv vorbereitet und hoffte, damit den Verlauf der Beratungen entscheidend beeinflussen zu können. Durch die gemeinsamen Erörterungen, so hoffte der SED-Chef insgeheim, würden alle Beteiligten so weit auf das Resultat verpflichtet sein, daß sie sich dessen Durchsetzung nicht mehr entziehen konnten. Zudem sollte der Kreml auf der Konferenz über die Verhandlungen mit den USA berichten und damit eine Diskussion über die dabei verfolgte Linie ermöglichen. ${ }^{110}$

Gegenüber Gromyko räumte DDR-Außenminister Bolz ein, der Verzicht auf das Berlin-Ultimatum habe eine Konfrontation mit dem Westen vermieden und die Möglichkeit geschaffen, einige Fragen in Übereinstimmung mit den USA zu lösen, was den weiteren Kampf erleichtere. Er könne aber die Schwierigkeiten nicht verschweigen, die in der DDR entstanden seien. Viele Versammlungen seien erforderlich gewesen, um die Bevölkerung von der Notwendigkeit einer Verschiebung zu überzeugen. Mit der Begründung, daß man einer Orientierung für die weitere politische Arbeit bedürfe, bemühte sich Bolz um eine Terminzusage für den Abschluß des Friedensvertrages und fragte, wann das bislang für November/ Dezember geplante Vorbereitungstreffen der Außenminister nunmehr stattfinden solle. Gromyko begegnete der Kritik mit dem Argument, daß eine im Konsens mit den Westmächten erreichte Friedensregelung vorteilhaft wäre, und betonte, daß sich die andere Seite zu Zugeständnissen bereit gezeigt habe. Er gab die Zusicherung, die UdSSR werde an ihrem prinzipiellen Standpunkt unbeugsam festhalten und auf voller Respektierung der DDR-Souveränität bestehen, selbst wenn die westlichen Staaten den Friedensvertrag vielleicht nicht unterschreiben würden. Diese hätten inzwischen eingesehen, daß sie eine völlig ablehnende Haltung nicht aufrechterhalten könnten. Das schaffe eine gute Ausgangsbasis für weitere Verhandlungen mit den USA. Eine Terminfestlegung für die Vorbereitungskonferenz erklärte der sowjetische Außenminister für noch nicht möglich, hielt aber Januar oder Februar für wahrscheinlich. ${ }^{111}$

109 Protokoll über die Besprechung beim Genossen Walter Ulbricht am 16. 9. 1961, SAPMO-BArch, DY 30/3509, Bl. 122-127. Das Bemühen um restriktive Formulierung zeigte sich auch bei den Korrekturwünschen zum sowjetischen Separatvertragsentwurf: Probleme und Aufgaben im $\mathrm{Zu}-$ sammenhang mit der Vorbereitung und dem Abschluß eines Friedensvertrags mit der DDR, o.D., PA-MfAA, C 845/75, B1. 243-252.

110 W. Ulbricht an N. S. Chruščëv, 30. 10. 1961, SAPMO-BArch, NY 4182/1206, Bl. 39.

111 Gespräch A. A. Gromyko - L. Bolz, 9. 11. 1961, AVPRF, 0742, 6, 43, 3, Bl. 15-20. Weniger genau wird das Gespräch wiedergegeben von DDR-Botschafter G. Dölling: Vermerk über Besprechung bei Gromyko, 9. 11. 1961, PA-MfAA, A 14870, Bl. 97. 
Im Gespräch mit einer DDR-Delegation betonte Chruschtschow, man müsse die Chance des diplomatischen Dialogs wahrnehmen. In der deutschen Frage stehe man gut da. Staatspräsident de Gaulle nehme die Existenz der zwei Staaten zur Kenntnis und würde es sogar vorziehen, wenn es drei Staaten gäbe. Mit der Bemerkung, die USA und Großbritannien fürchteten eine separate Übereinkunft zwischen der UdSSR und der Bundesrepublik und suchten diese unbedingt zu verhindern, deutete der Kremlchef eine zusätzliche Möglichkeit an, Dissens im Westen zur Durchsetzung östlicher Ziele zu nutzen. Im übrigen hatte die ostdeutsche Seite nach seiner Ansicht bereits das Wesentliche erhalten. Ihre Bedürfnisse seien doch durch die Abriegelung West-Berlins befriedigt worden. An dessen Grenze herrschten nunmehr „klare Verhältnisse“. Die Stadt sei „von der DDR praktisch eingeschlossen“. Zur Sorge über dortige „Bemühungen“ Westdeutschlands gebe es keinen Grund, denn die Sowjetunion könne jederzeit die notwendigen Maßnahmen dagegen ergreifen. Das hätten auch die Kapitalisten begriffen, wie die Abwanderung von Betrieben und Einwohnern zeige.112

\section{Ergebnisloser Meinungsaustausch mit den USA}

Von Bonn und Paris mißtrauisch beobachtet, begannen die formellen amerikanisch-sowjetischen Gespräche. Am 29. September 1961 richtete Chruschtschow einen Appell an Kennedy, der eingetretenen Verschärfung der wechselseitigen Beziehungen Einhalt zu gebieten und die Spirale von Maßnahmen und Gegenmaßnahmen im Rüstungsbereich zu beenden. Man müsse Bedrohungen des Friedens abwenden. Das sei ohne Friedensvertrag unmöglich. Als „vernünftige Stellungnahme“ stellte er eine Äußerung General Clays heraus, daß sich die Bundesrepublik mit der Zweistaatlichkeit abzufinden habe. Sollte der Abschluß eines Friedensvertrags für beide Staaten auf Schwierigkeiten stoßen, könne man doch zwei Verträge ähnlichen Inhalts - den einen mit der DDR und den anderen mit der Bundesrepublik - schließen. Damit müßten die Anerkennung der bestehenden Grenze und die Lösung der West-Berlin-Frage einhergehen. Für das zweitgenannte Problem gab es, wie der sowjetische Führer erklärte, keine bessere Regelung als die „Freie Stadt“. Dadurch trete an die Stelle des bisherigen überholten Zustands - mithin des westlichen Besatzungsregimes - ein stabilerer Status. Garantien würden die Freiheit West-Berlins und seiner Außenverbindungen gewährleisten. Auf dieser Grundlage werde es zur Beendigung des Kalten Krieges kommen. ${ }^{113}$ Damit erklärte der Kremlchef zwar den Willen zu Einvernehmen und Entspannung, ging aber von keiner der bisherigen Forderungen ab.

Die Hoffnung Chruschtschows, Kennedy werde sich aufgrund seines offenkundigen Interesses an einer Verständigung zur Annahme der sowjetischen For-

112 Botschafter Dölling an Staatssekretär Winzer, 17. 11. 1961, PA-MfAA, G-A 478, Bl. 21-24.

113 N. S. Chruščëv an J. F. Kennedy, 29. 9. 1961, AVPRF, 0129, 45, 329, 12, Bl. 72-89/FRUS 19611963, XIV, S. 444-455/FRUS 1961-1963, Bd. VI: Kennedy-Khrushchev Exchanges, Washington 1996, S. 25-38. Vgl. den Entwurf des sowjetischen Außenministeriums vom 28. 9. 1961, AVPRF, $0129,45,329,12$, B1. 51-66. 
derungen bewogen sehen, wurde enttäuscht. Am 16. Oktober trat der Präsident in seinem Antwortschreiben dem Mißverständnis entgegen, daß er den Vorstellungen des Kreml zustimme, wenn er wie dieser die Lage in Berlin und Deutschland als anomal betrachte. Die fehlende Normalität liege nicht an fortbestehenden „Überresten des Krieges“, sondern daran, daß die deutsche Nation durch zwei Besatzungsarmeen geteilt werde. Nicht das Erbe des Zweiten Weltkrieges bedrohe den Frieden, sondern die Gefahr eines dritten. In der Region herrsche Frieden, der durch den geforderten Vertragsschluß nur gefährdet werden könne. Würde die Wahrung wesentlicher Interessen der USA vom ostdeutschen Regime abhängig gemacht werden, wäre der bisherige Frieden bedroht. Es gab demnach keinen Grund, die Lage West-Berlins zu verändern.114

Chruschtschow lehnte in seiner Antwort vom 9. November eine weitere Hinnahme der bisherigen Verhältnisse kategorisch ab. Es gelte, das „schwere Erbe“ West-Berlin zu überwinden. Davon habe im übrigen auch Kennedy gesprochen. Das Besatzungsregime dürfe keinesfalls weiter aufrechterhalten werden. Gemäß früherem Vorschlag bot der Kremlchef an, daß in der Teilstadt symbolische Kontingente von Truppen entweder aller Vier Mächte (also auch der UdSSR) oder - aufgrund eines UNO-Auftrags - Einheiten neutraler Staaten stationiert werden könnten. Außerdem sei denkbar, daß man nicht einen einzigen Friedensvertrag abschließe, sondern - separat mit jeweils einem deutschen Staat - deren zwei. Chruschtschow erteilte der westlichen Idee eine Absage, daß die Sowjetunion ihren Vertrag mit der DDR schließen könne, ohne daß dadurch die westlichen Besatzungsrechte beseitigt würden. Die DDR müsse unbedingt die Kontrolle über die Zugangswege erhalten. Er unterstellte, ihr unterstehe bereits der - künftig allein noch aktuelle - zivile West-Berlin-Verkehr. Bei dessen Abwicklung habe es keine Probleme gegeben. Daher sei nicht zu verstehen, was der Westen gegen die Regelung habe. ${ }^{115}$

Obwohl Botschafter Thompson in Moskau zu denjenigen Amerikanern gehörte, die dem Kreml eine bloß defensive Ausrichtung seiner Politik zuschrieben und zudem für eine Übereinkunft ohne Rücksicht auf die Verbündeten eintraten, überzeugten ihn die sowjetischen Stellungnahmen davon, daß die UdSSR zu keinerlei Nachgeben bereit sei. ${ }^{116}$ Kennedy, für den das Urteil des Diplomaten großes Gewicht hatte, zog anscheinend den gleichen Schluß.117 Trotzdem bemühte er sich weiter um eine Verständigung. Er appellierte an den Kremlchef, die gegensätzlichen Positionen beiseite zu lassen und sich der Verantwortung für die gegenwärtige Situation zu stellen. Nach seiner Ansicht mußte eine künftige Abmachung unbedingt von drei Tatbeständen ausgehen. Erstens stünden die westlichen Trup-

114 J. F. Kennedy an N. S. Chruščëv, 16. 10. 1961, in: FRUS 1961-1963, XIV, S. 502-508/FRUS 19611963, VI, S. 38-44. In gleichem Sinne argumentierte Kennedy in dem Interview, das er Chruščëvs Schwiegersohn Adžubej am 25.11. 1961 gab (Dokumente zur Deutschlandpolitik, a.a.O., S. 993).

115 N. S. Chruščëv an J. F. Kennedy, 9. 11. 1961, in: FRUS 1961-1963, XIV, S. 567-580/FRUS 19611963, VI, S. 45-57.

116 Letter From the Ambassador to the Soviet Union to Secretary of State Rusk, 27.11. 1961, in: FRUS 1961-1963, XIV, S. 634-636.

117 Vgl. seine Darstellung des Konflikts um Berlin im Interview mit A. Adžubej am 25. 11. 1961, in: Dokumente zur Deutschlandpolitik, a.a.O., S. 993, $994 \mathrm{f}$. 
pen in West-Berlin. Solange es die Bevölkerung wolle, würden sie dort bleiben. Zweitens wolle die Bevölkerung die sowjetischen Streitkräfte dort nicht haben; ihre Anwesenheit in der Teilstadt werde zur Gewährleistung des westlichen Zugangs weiterhin nicht benötigt. Drittens hätten die Zugangsrechte der Westmächte schon vor Gründung der DDR durch durch die UdSSR bestanden und könnten daher nicht durch einen Vertrag zwischen diesen beiden Staaten aufgehoben werden. Diese Verhandlungsbasis schließe amerikanisch-sowjetische Gespräche zur „Klärung und möglichen Verbesserung der Zugangsrechte“ nicht aus, doch mußten diese nach Auffassung des Präsidenten unbedingt gewahrt werden, wenn es zu einer Verständigung kommen sollte. ${ }^{118}$ Kennedy erläuterte Chruschtschows Schwiegersohn Adshubej, was er konkret im Auge hatte: Eine „internationale Verwaltung der Autobahn“ zwischen West-Berlin und der Bundesrepublik sollte gewährleisten, „daß Güter und Personen frei hinein- und herausgebracht werden können." 119

Der Kremlchef war nicht bereit, diese Vorstellungen zu akzeptieren. Sein Widerspruch galt vor allem der militärischen Anwesenheit der Westmächte in West-Berlin und dem damit verknüpften Zugangsrecht. Die westlichen Soldaten seien nicht von der Bevölkerung in die Stadt gerufen worden, sondern seien als Besatzer dorthin gekommen. Eine Okkupation lasse sich nicht ewig ausdehnen. Jetzt müsse damit Schluß sein. Die UdSSR sei nicht willens, weiter als Verkehrspolizei für den Verkehr der feindlichen NATO-Truppen zu dienen, und werde niemals einer Verlängerung der Besatzungsverhältnisse zustimmen, sondern für ihr Recht und für die Normalisierung der Lage in der Mitte Europas kämpfen. Chruschtschow erklärte, er bestehe keineswegs darauf, sowjetische Einheiten in West-Berlin zu stationieren. Die Anregung dazu sei von den USA ausgegangen, die der UdSSR die Verantwortung einer Garantiemacht zugedacht hätten. Auf diese Rolle würde er gerne verzichten. Er verlangte die Aufnahme beider deutscher Staaten in die UNO und bot an, schon vor Abschluß des Friedensvertrags mit der DDR könne man den Freistadtstatus West-Berlins aushandeln. ${ }^{120}$ Auf der Grundlage dieses Vorschlags war zwar zu erwarten, daß die östliche Seite auf eine Friedensregelung vor einer Übereinkunft über die Zukunft der Stadt verzichtete, aber damit war kein Abrücken des Kreml von der Forderung nach uneingeschränkter Annahme seiner Regelungsvorschläge durch die Westmächte verbunden.

118 J. F. Kennedy an N. S. Chruščëv, 2. 12. 1961, in: FRUS 1961-1963, XIV, S. 643-646/FRUS 19611963, VI, S. 65-68.

119 Text: Dokumente zur Deutschlandpolitik, a.a.O., S. $985-998$ (Zitat auf S. 995). Das am 25. 11. 1961 gegebene Interview wurde - als erste amerikanische Stellungnahmen seit Jahren - drei Tage später in den „Izvestija“ im vollen Wortlaut wiedergegeben. Das läßt sich als Hinweis werten, daß der Kreml, der völlig gegensätzlichen Positionen ungeachtet, weiterhin sehr an Verhandlungen mit den USA interessiert war.

120 N. S. Chruščëv an J. F. Kennedy, 13. 12. 1961, in: FRUS 1961-1963, XIV, S. 681-691/FRUS 19611963, VI, S. 69-78. 


\section{Fallstricke der amerikanischen Konzessionsbereitschaft}

Am Jahresende waren die beiderseitigen Positionen geklärt worden, ohne daß es zur Annäherung gekommen wäre. Kennedy war aber weiter an Verhandlungen interessiert. Da Chruschtschow die gleiche Haltung einnahm, wollten beide den brieflichen Kontakt und die Gespräche fortsetzen. Weil man in Washington eine Vier-Mächte-Konferenz für verfrüht hielt, kamen nur Sondierungen in Betracht, mit denen zunächst Außenminister Gromyko und Botschafter Thompson beauftragt wurden. Ihre Ergebnisse sollten späteren vierseitigen Verhandlungen nicht vorgreifen. Es sollten nach offiziellem Bekunden keine vollendeten Tatsachen geschaffen werden, die Briten und Franzosen dann zu übernehmen hätten. Es hieß, daß nur der Weg zur Einigung zwischen allen beteiligen Staaten geebnet werden solle. Es war jedoch klar, daß eine fertige Übereinkunft zwischen USA und UdSSR den anderen Staaten kaum noch ein Nein erlauben würde. Um den Argwohn der Verbündeten abzubauen, daß sie nur noch hinterher Ja und Amen sagen sollten, stellten die Amerikaner ihnen die Linie ihres Vorgehens zur Diskussion.

Dabei stießen die amerikanischen Vorstellungen über einen Berlin-Kompromiß mit der UdSSR auf starken Widerstand in Paris und Bonn. Das wurde Kennedy bei Adenauers Besuch in Washington vom 20. bis 22. November ${ }^{121}$ und durch das Außenministertreffen der vier wichtigsten NATO-Staaten in Paris vom 10. bis 12. Dezember ${ }^{122}$ deutlich vor Augen geführt. Der französische Staatspräsident de Gaulle lehnte Verhandlungen prinzipiell ab, wenn man unter Druck stehe und mit einem Gegner zu tun habe, der in allen wichtigen Punkten von vornherein nichts als den eigenen Standpunkt gelten ließ. Der Bundeskanzler wandte sich vor allem gegen Kennedys Angebot, das Besatzungsrecht durch ein anderes Arrangement zu ersetzen, weil nach seiner Einschätzung damit entscheidend wichtige Positionen preisgegeben wurden. Man könne das Schicksal West-Berlins nicht von der politischen Standfestigkeit der UNO bzw. kleiner neutraler Staaten abhängig machen. ${ }^{123}$ Der Bundeskanzler begegnete zudem den Bemühungen um eine Verständigung über die Zukunft der Stadt generell mit Sorge. Wie er befürchtete, würden sich die Verhandlungen nicht auf Berlin begrenzen lassen. Dem Kreml biete sich damit die Aussicht, die Forderung nach Herstellung eines Zusammenhangs mit der Deutschland-Politik und den Abrüstungsfragen durchzusetzen und auf dieser Basis Siege auf breiter politischer Front zu erringen. ${ }^{124}$

In Washington entstand trotzdem kein klares Bild der Bonner Haltung. Das hatte mehrere Gründe. Adenauer sah, daß Kennedys Verhandlungseifer nicht zu

121 Vgl. die Dokumente in: FRUS 1961-1963, XIV, S. 588-634.

122 Vgl. die Dokumente ebd., S. 650-681.

123 Zur Haltung Adenauers siehe Rolf Steininger, Der Mauerbau. Die Westmächte und Adenauer in der Berlinkrise 1958-1963, München 2001, S. 318-324. Zur Haltung des französischen Staatpräsidenten siehe Document 02941, Crisis Over Berlin. American Policy Concerning the Soviet Threats to Berlin, November 1958-December 1962. Part VI: June-September 1961, Research Project No. 614-F, April 1970, Department of State (Documents from the National Security Archive, microfiches published by Chadwyck-Healey Inc.), S. 93, $125 \mathrm{f} ., 128 \mathrm{f}$.

124 Vgl. im einzelnen Horst Osterheld, „Ich gehe nicht leichten Herzens ...“ Adenauers letzte Kanzlerjahre - ein dokumentarischer Bericht, Mainz 1987 (2. Aufl.), S. 82-92; Wilhelm G. Grewe, Rückblenden. Aufzeichnungen eines Augenzeugen deutscher Außenpolitik von Adenauer bis Schmidt, Frankfurt/Main 1979, 498-535. 
stoppen war, und suchte sich daher bei aller Skepsis auf dessen Kurs einzustellen. Zudem wurden die Konturen seiner Berlin-Politik nach außen hin von Außenminister Schröder verwischt. Dieser fürchtete, die USA könnten ohne rechtzeitige Übereinkunft mit der UdSSR in eine militärisch unhaltbare Lage geraten und dann zur politischen Kapitulation genötigt sein. Er neigte daher den Kompromißvorstellungen des amerikanischen Präsidenten zu und konterkarierte mit seinen Äußerungen den bremsenden Einfluß, den die Bundesregierung in Washington geltend zu machen suchte. ${ }^{125}$ Ungeachtet dieser Opposition im Auswärtigen Amt, war Adenauer der bestimmende Akteur in Bonn. Der Rückhalt am gaullistischen Frankreich erlaubte ihm, seine Position zu vertreten, ohne eine Isolierung im Kreise der westlichen Staaten befürchten zu müssen. ${ }^{126}$ Vor diesem Hintergrund zeichnete sich im Herbst 1961 eine Konstellation ab, die Kennedys Bemühen um Einigung mit der UdSSR mit erheblichen Risiken belastete. Die mehr oder weniger offen geäußerte Ablehnung Frankreichs und der Bundesrepublik gegenüber der Politik des Präsidenten, dem Verlangen Chruschtschows weit entgegenzukommen, stellte potentiell die Einheit des westlichen Bündnisses in Frage, auf das sich die USA gegenüber der Sowjetunion angewiesen sahen.

Im Kreml wurde nicht erkannt, daß damit die Durchsetzung der Berlin-Ziele selbst dann fraglich war, wenn es gelang, die Zustimmung der Amerikaner zu erlangen. Statt dessen blickte man auf die Differenzen unter den westlichen Staaaten, vor allem zwischen den Vereinigten Staaten und der Bundesrepublik, und stellte befriedigt fest, daß Adenauer mit seiner Berlin- und Deutschland-Politik in eine schwierige Lage geraten war und daß er die Gespräche zwischen Washington und Moskau, von denen eine Verschärfung seiner Bedrängnisse zu erwarten war, nicht verhindern konnte. ${ }^{127}$ Der Gedanke, daß eine in die Enge getriebene Bundesregierung sich möglicherweise mit Erfolg gegen amerikanische Konzessionen an die UdSSR wenden könnte, weil die USA im Interesse des Zusammenhalts in der NATO Rücksichten auf den westdeutschen Verbündeten und auf Frankreich zu nehmen hatten, war der sowjetischen Führung völlig fremd. Ihre dominierende Stellung im Warschauer Pakt verschloß ihr den Blick dafür, daß in der westlichen Allianz andere Regeln des Zusammenwirkens galten.

125 Thomas Opelland, Gerhard Schröder (1910-1989), Düsseldorf 2002, S. 448.

126 Vgl. Wilhelm G. Grewe, Rückblenden 1976-1951, Frankfurt/Main 1979, S. 489.

127 A. Smirnov an I. I. Il'ičëv (mit Anlage: Ob otnošenii pravitel'stva FRG k peregovoram po berlinskomu voprosu), 14. 12. 1961, AVPRF, 0757, 6, 51, 47, Bl. 115-124. 